\title{
Estabilização da geração de colunas aplicada no problema de corte de estoque
}

\author{
Marco Antonio Lozano Porta Lopes ${ }^{1}$
}

Orientador: Prof. Dr. Marcos Nereu Arenales

Dissertação apresentada ao Instituto de Ciências Matemáticas e de Computação - ICMC-USP, como parte dos requisitos para obtenção do título de Mestre em Ciências de Computação e Matemática Computacional.

USP - São Carlos - SP

Fevereiro de 2006

\footnotetext{
${ }^{1}$ Bolsista da Fapesp.
} 
Estabilização da geração de colunas aplicada no problema de corte de estoque

Marco Antonio Lozano Porta Lopes 


\section{Agradecimentos}

Ao meu orientador Marcos Nereu Arenales pela orientação, dedicação, amizade e principalmente, pela confiança depositada nesse trabalho e nos próximos. Agradeço a Selma H. V. Arenales pelo auxílio e dedicação em ensinar os primeiros passos de uma caminhada que espero ser longa.

A Claudete Lozano minha mãe, como exemplo de perseverança, honestidade e pelo apoio em todas as etapas da vida. Ao meu avô Francisco Lozano pelo grande homem que foi e que sempre será em minha memória.

A minha noiva Paula pelo amor, paciência e pela presença nos momentos bons e maus.

Aos professores e funcionários do ICMC-USP que contribuíram com este trabalho.

A todos os meus amigos por estarem ao meu lado em todos os momentos.

A FAPESP pela credibilidade e apoio financeiro.

E por fim a todos que colaboraram indiretamente na realização deste trabalho. 


\section{Resumo}

O problema de corte de estoque consiste em cortar objetos maiores, disponíveis em estoque, para produzir uma quantidade especificada de peças menores, de modo que uma certa função objetivo seja otimizada. Um modelo de otimização linear tem sido amplamente utilizado na solução deste problema desde os anos 60 , que incorpora parte da estrutura combinatória inerente ao problema na construção das colunas da matriz de restrições. As colunas são construídas a cada iteração do Método Simplex, chamandose geração de colunas. Apesar do método Simplex ser largamente utilizado para este tipo de problema, apresenta baixa convergência quando próximo da otimalidade, pouco melhorando a função objetivo. Assim, estratégias para aceleração do Método Simplex faz-se necessário, uma maneira consiste na redução do espaço dual, com a introdução de restrições (colunas no primal) que evite grandes variações nas variáveis duais, chamadas cortes duais. Neste trabalho, generalizamos duas famílias de cortes duais recentemente publicadas e analisamos o impacto computacional desses cortes duais sobre a convergência do Método Simplex. 


\section{Abstract}

The cutting stock problem consists of cutting large available objects in stock to produce a quantity of ordered smaller itens, in such a way as to optimize a given objective function. A linear optmizatim model has been widely used to solve this problem since the $60 \mathrm{~s}$, in which part of a combinatorial structure of the problem is embedded. The columns of the constraint matrix are generated in each iteration of the Simplex Method, called the column generation technique. Although, the Simplex Method is widely used, it has a low convergence near to optimality. In this way, strategies to accelerate the Simplex Method are welcome which can be obtained by adding dual cuts (primal columns). The goal of this work is to study published dual cuts and to proposed others. In this book us extend two families of dual cuts, which were recently published, and analyse the computational impact of these dual cuts on the converge of the Simplex Method 


\section{Conteúdo}

LISTA DE TABELAS . . . . . . . . . . . . . . . . . . iii

LISTA DE FIGURAS . . . . . . . . . . . . . . . . . iv

1 Introdução 1

1.1 Organização da Monografia . . . . . . . . . . . . . . . 6

2 Revisão Bibliográfica Básica $\quad 8$

2.1 Problema de Corte de Estoque Unidimensional . . . . . . . . . . . . . . . 9

2.1.1 Modelo Inicial . . . . . . . . . . . . . . . . . . . . . . 9

2.1.2 Modelagem dos problemas com vários tipos de barras em estoque em quantidades limitadas . . . . . . . . . . . . . . . . 12

3 Revisão Bibliográfica Específica $\quad 16$

3.1 Processo de Geração de Colunas e o espaço dual . . . . . . . . . . . . . 16

3.2 Cortes Duais . . . . . . . . . . . . . . . . . . . 18

3.2.1 Uma Família de cortes duais para os itens . . . . . . . . . . . . 19

3.2.2 Uma nova interpretação dos cortes duais para os itens . . . . . . . . 20

3.2.3 Recuperando a solução do problema primal . . . . . . . . . . . . . 21

3.2.4 Proposta para uma nova família de cortes duais . . . . . . . . . . 28

3.2.5 Uma Família de cortes duais para os objetos . . . . . . . . . . . 30

3.2.6 Uma nova interpretação dos cortes duais para os objetos . . . . . . 31

3.2.7 Recuperando a solução do problema primal . . . . . . . . . . . . . . 32

3.2.8 Proposta para uma nova família de cortes duais . . . . . . . . . . 34

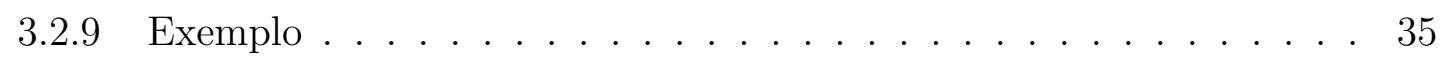

4 Experimentos Computacionais $\quad 37$ 
Referências bibliográficas

A Método Simplex e a técnica de geração de colunas

A.0.10 Algoritmo do Método Simplex com Geração de Colunas Aplicado no Problema de Corte de Peças em Estoque . . . . . . . . . . . 50

B Prova da afirmação da seção 2.1.1 53 


\section{LISTA DE TABELAS}

Pagina

4.1 Classes dos testes (média de 10 exemplos em cada classe) . . . . . . . 38 


\section{LISTA DE FIGURAS}

\section{Pagina}

1.1 (a) Objeto a ser cortado; (b) 3 tipos de itens demandados (c) padrão de corte: forma de se cortar um objeto.

1.2 (a) Objeto em estoque $L \times W$ a ser cortado; (b) 4 tipos de itens demandados (c) padrão de corte: forma de se cortar um objeto. . . . . . . . . . . . . . . 3

1.3 (a) Objeto em estoque; (b) 5 tipos de itens demandados (c) Uma forma de

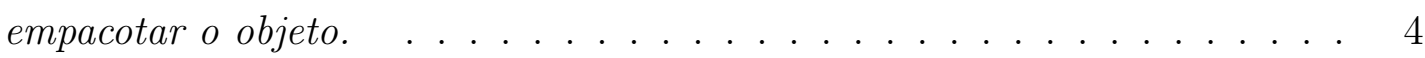

1.4 Valor da função objetivo pelo número da iteração. . . . . . . . . . . . . 5

1.5 Variação da norma do vetor multiplicador simplex. . . . . . . . . . . . . 6

2.1 (a) Objeto a ser cortado; (b) itens demandados; (c) exemplos de padrões

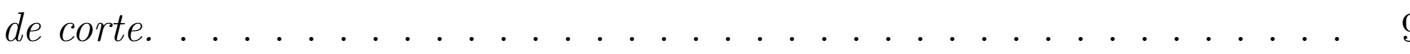

3.1 Geração de colunas no espaço dual. . . . . . . . . . . . . . . . . . . 18

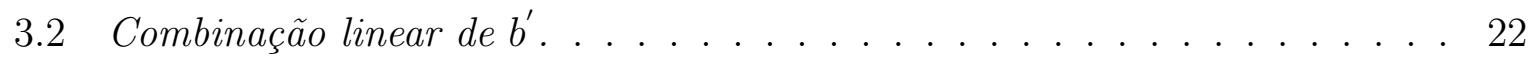

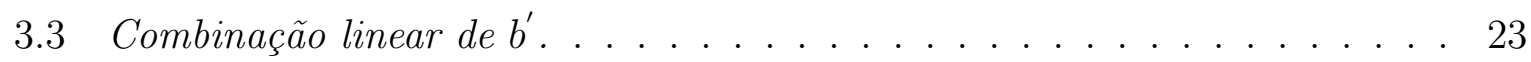

3.4 Combinação linear de $b^{\prime} \ldots \ldots \ldots \ldots$. . . . . . . . . . . . . 24

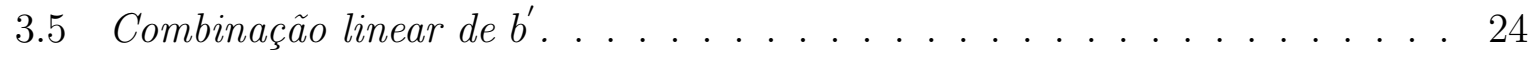

3.6 Corte dual básico e estendido. . . . . . . . . . . . . . . . . . . . . . . . 29

4.1 Variação da norma do vetor multiplicador simplex, caso corte dual básico $|S|=1$. 
4.2 Variação da norma do vetor multiplicador simplex, caso corte dual estendido $|S|=1 \ldots \ldots \ldots \ldots \ldots \ldots \ldots \ldots$

4.3 Variação da norma do vetor multiplicador simplex, caso com todos os cortes

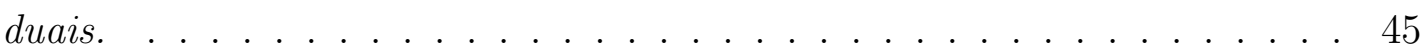




\section{Capítulo 1}

\section{Introdução}

A otimização linear consiste na minimização ou maximização de uma função linear, definida sobre um domínio descrito por equações e/ou inequações lineares, ou seja:

$$
\begin{aligned}
& \text { minimizar } f(x)=\sum_{j=1}^{n} c_{j} x_{j} \\
& \text { sujeito } a:\left\{\begin{array}{l}
\sum_{j=1}^{n} a_{i j} x_{j}=b_{i} \quad i=1, \ldots, m \\
x_{j} \geq 0 \quad j=1, \ldots, n
\end{array}\right.
\end{aligned}
$$

sendo que $a_{i j}, b_{i}, c_{j}$ são dados e $x_{j}$ as incógnitas a determinar de modo a minimizar $f(x)$.

A otimização linear é um dos modelos de otimização mais utilizado na prática, como por exemplo, no planejamento e controle da produção, corte de peças, no planejamento de recursos hídricos, cálculo estrutural e muitos outros aspectos na tomada de decisão em problemas industriais e econômicos.

Dentre os exemplos citados nos ateremos ao problema de corte de peças. A otimização do processo de corte de peças maiores, disponíveis em estoque, para a produção de peças menores, em quantidades encomendadas, tem sido objeto de intensos estudos há 4 décadas, desde os trabalhos pioneiros de Gilmore e Gomory ([4],[5] e [6] ). Trata-se de um problema importante (devido a várias aplicações industriais) e interessante (devido à complexidade computacional).

George B. Dantzig propôs em 1947 o Método Simplex para resolver problemas de otimização linear. Desde então, um número grande de pesquisadores tem contribuído 
para o campo da otimização linear de diferentes maneiras, incluindo desenvolvimentos teóricos, aspectos computacionais e novas aplicações. Em 1961, Gilmore e Gomory, desenvolveram a técnica de geração de colunas para resolver o problema de corte de estoque, que incentivaram inúmeras pesquisas na área de corte e empacotamento.

A abordagem por otimização linear desfruta de ampla aceitação por causa da habilidade de modelar problemas importantes e complexos e na capacidade de seus métodos para produzir soluções em tempo razoável. Hoje em dia, problemas com milhares de restrições e variáveis são resolvidos em microcomputadores. Em particular, o desenvolvimento de variações e implementações mais eficientes é uma constante preocupação nestes cinqüenta anos do método simplex.

\section{Problemas de corte}

Uma primeira característica para classificar os problemas de corte é as dimensões relevantes para o corte, dadas abaixo. Outras características podem ser encontradas em Dickhoff 1990.

\section{Unidimensional}

Um problema é dito unidimensional quando apenas uma dimensão é relevante no processo de corte. Sua formulação e métodos de resolução serão tratados neste trabalho nas seções a seguir. Veja Figura (1.1).

Problemas de corte unidimensional têm várias aplicações industriais, como por exemplo, na indústria de papel, onde grandes rolos têm de ser cortados em tamanhos encomendados; na indústria de aço, onde bobinas de aço são cortadas em bobinas menores e, também, na indústria de alumínio, onde um produtor de perfis de alumínio fornece aos clientes o serviço de calcular o número mínimo de peças necessárias para atender aos pedidos.

A ênfase desta dissertação está em problemas de corte unidimensionais. 
(a)

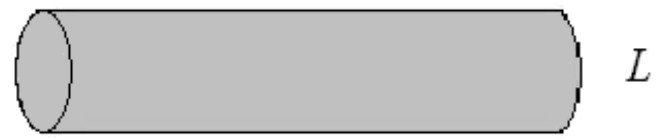

(b)

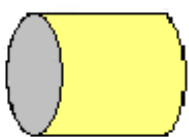

$l_{7}$

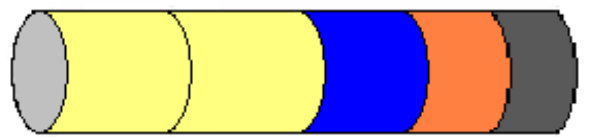

Figura 1.1: (a) Objeto a ser cortado; (b) 3 tipos de itens demandados (c) padrão de corte: forma de se cortar um objeto.

\section{Bidimensional}

O problema é dito bidimensional quando duas dimensões (comprimento e largura) são significativas no processo de cortagem. Resolver este tipo de problema consiste em combinar geometricamente os itens ao longo do comprimento e da largura das peças em estoque, como ilustra a Figura (1.2). Este tipo de problema ocorre, por exemplo, em indústrias de placas de vidro, de madeira e móveis.

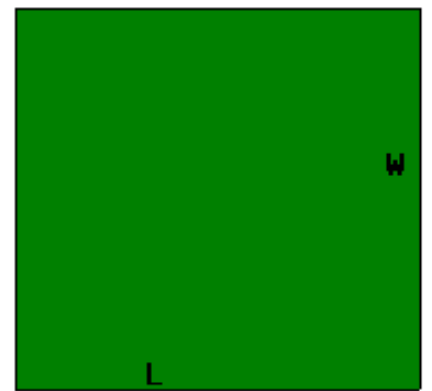

(a)

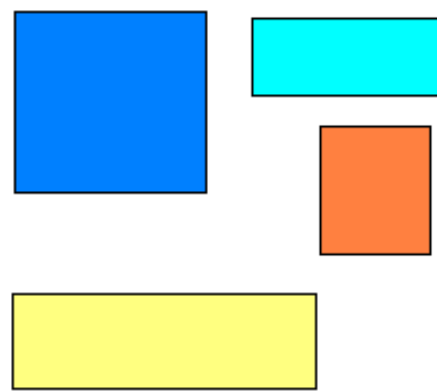

(b)

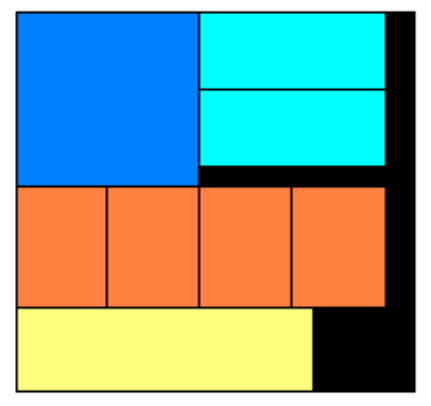

(c)

Figura 1.2: (a) Objeto em estoque $L \times W$ a ser cortado; (b) 4 tipos de itens demandados (c) padrão de corte: forma de se cortar um objeto.

\section{Tridimensional}

No problema tridimensional as três dimensões são significativas no processo de 
cortagem. Este tipo de problema é aplicado, por exemplo, em indústrias de espuma para a produção de colchões e travesseiros. No entanto, suas aplicações mais interessantes são na solução de um problema inverso ao de corte, o chamado Problema de Empacotamento, que consiste, basicamente, em empacotar unidades pequenas dentro de uma unidade grande, de tal forma que um certo objeto seja otimizado; por exemplo, arranjar o maior volume possível de caixas dentro de um contêiner, como ilustra o exemplo da Figura (1.3).

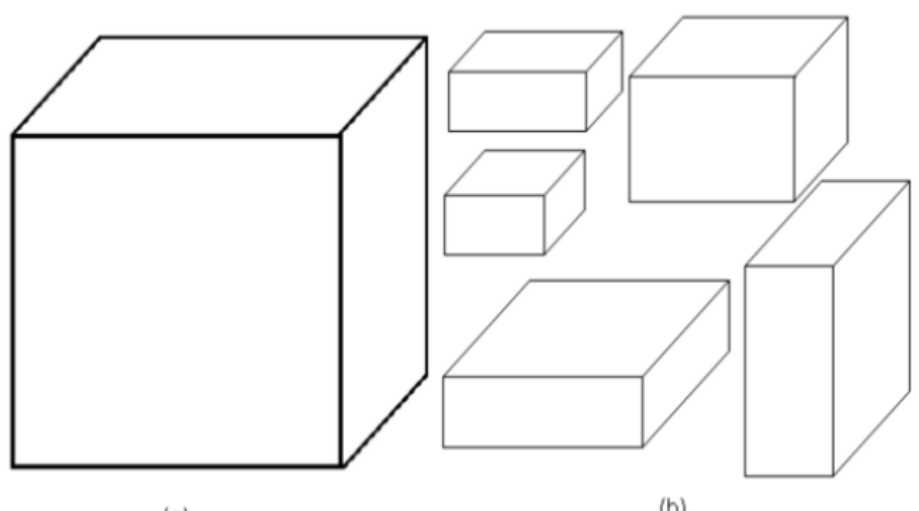

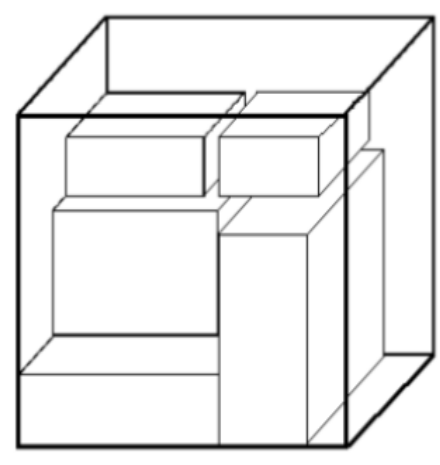

(c)

Figura 1.3: (a) Objeto em estoque; (b) 5 tipos de itens demandados (c) Uma forma de empacotar o objeto.

\section{5 e 2.5-dimensional}

Analisando a geometria, podemos encontrar problemas do tipo 1.5 dimensional, que são essencialmente problemas bidimensionais, porém, é considerado uma das dimensões variável. Um exemplo desse tipo de problema é o de um rolo de tecido que tem largura fixa e comprimento suficiente grande para a produção de roupas, o comprimento mínimo é tipicamente o objetivo desses problemas. Podemos encontrar também, problemas do tipo 2.5-dimensional, que também podem ser considerados como um problema tridimensional, ou seja, três dimensões são relevantes para o problema, porém uma delas é variável. Um exemplo seria um contêiner com largura e comprimento fixas e suficientemente alto para acomodar um volume da carga em que a altura mínima seria desejada. 


\section{Objetivos da dissertação}

Apesar do Método Simplex com geração de colunas ser um método eficiente, e em geral apresentar convergência rápida sabemos que quando nos aproximamos da otimalidade ele converge lentamente. Na Figura (1.4) ilustramos a convergência de um problema de corte de estoque (barra de comprimento $500 \mathrm{~cm}$ e 45 itens de vários comprimentos) resolvido pelo método de geração de colunas. Na iteração de número 270 o valor da função objetivo é 1733 e na iteração 331 (quando a otimalidade foi encontrada) é 1726. Notamos que a função objetivo decresceu de 7 unidades em 161 iterações. Esta característica é típica na geração de colunas e é chamada de "cauda "( tail ).

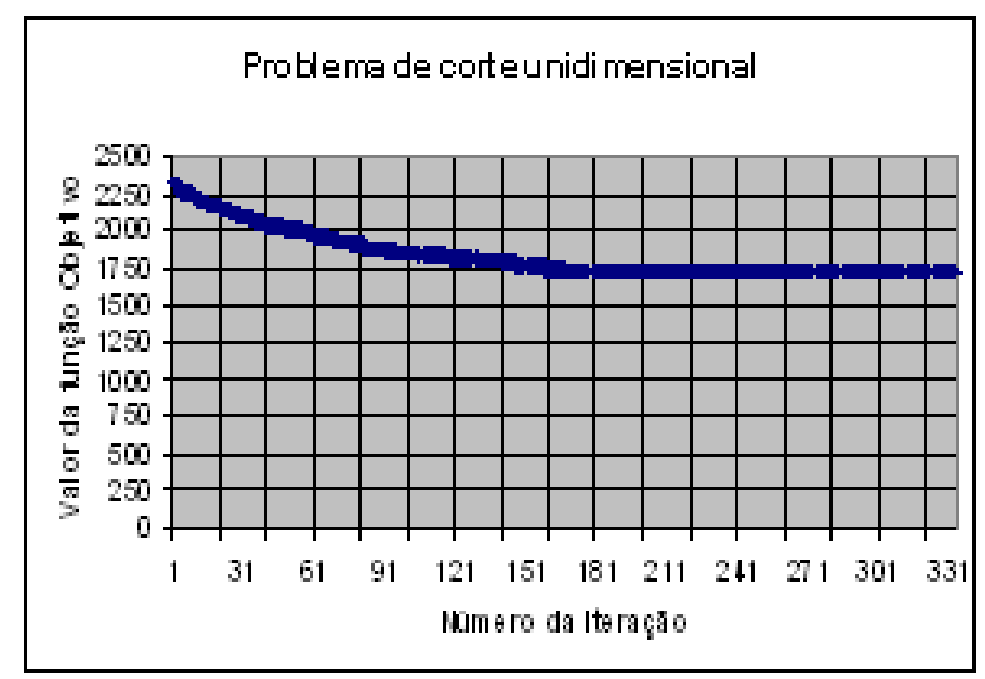

Figura 1.4: Valor da função objetivo pelo número da iteração.

Além da cauda perto da otimalidade podemos identificar uma grande variação das variáveis duais, como ilustra a Figura (1.5). 


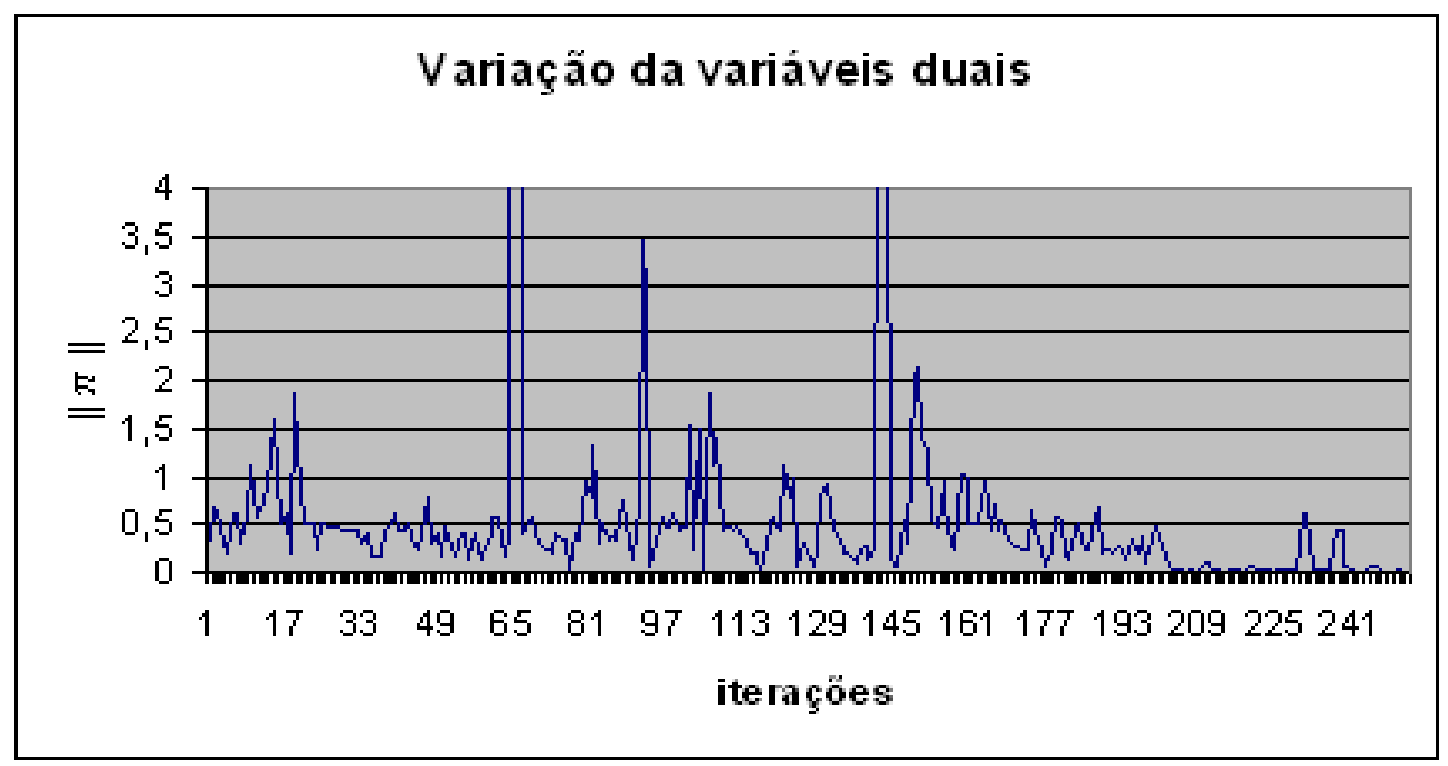

Figura 1.5: Variação da norma do vetor multiplicador simplex.

Por causa desses problemas, métodos de aceleração e estabilização surgem como uma forma de superar estes inconvenientes.

Os objetivos principais desta dissertação podem ser resumidos como:

a) Estudar e generalizar os cortes duais propostos por Valério de Carvalho [13], cujo o objetivo é acelerar a geração de colunas pela introdução de restrições duais;

b) implementar os cortes duais com a técnica de geração de colunas e comparar com o Método Simplex com geração de colunas habitual (sem cortes duais).

\subsection{Organização da Monografia}

No Capítulo 2, apresentamos uma breve revisão bibliográfica, comentando algumas publicações relacionadas ao assunto do trabalho, em ordem cronológica. Apresentamos também o problema de corte unidimensional e a modelagem matemática do problema de corte de estoque unidimensional. Em relação à resolução do problema, explicitamos um método de resolução (Método Simplex com Geração de Colunas) seguido de seu algoritmo que pode ser visto no anexo A.

No capítulo 3, apresentamos uma continuação da revisão bibliográfica referente a publicações relacionadas à aceleração e estabilização do Método Simplex com geração de colunas. É mostrada a estratégia de Valério de Carvalho [13]. 
No capítulo 4 apresentamos os resultados computacionais em que comparamos o Método Simplex com a técnica geração de colunas habitual, com os cortes duais de Valério de Carvalho e com as nossas generalizações.

No capítulo 5 apresentamos nossas conclusões e as propostas futuras para o trabalho relacionado com os cortes duais.

Por fim temos a bibliografia utilizada. 


\section{Capítulo 2}

\section{Revisão Bibliográfica Básica}

Por volta de 1940, problemas de corte de estoque começaram a ser estudados, sob a ótica de pesquisa operacional, embora as principais pesquisas surgiram nos anos 60 .

Na década de 60 foram publicados trabalhos importantes na área. As modelagens e métodos de resolução de maior repercussão na literatura foram publicados por Gilmore e Gomory[4], os mesmos que apresentaram o Método Simplex com geração de colunas para um modelo de otimização linear (uma aproximação do problema) que, pela primeira vez, resolveu problemas práticos de corte unidimensional. Em 1963, Gilmore e Gomory apresentaram um novo método para o problema da mochila e um estudo de caso no corte de papel. Também apresentaram um novo modelo para balancear carga em máquinas, o qual é hoje usado para tratar problemas com objetos em estoque de diferentes tamanhos.

No inicio da década de 80, foram propostas algumas modificações no algoritmo de Gilmore e Gomory por Haessler [7] , ampliando o objetivo de minimizar a perda de material. Tais modificações se referem aos procedimentos que geram a solução inicial e na geração dos padrões a entrar na base. Segundo o autor, controlar a geração dos padrões a entrar na base e usar uma formulação mais restrita, porém menos eficiente, do problema da mochila, ajuda a reduzir problemas de arredondamento e mudanças de padrões de corte. 


\subsection{Problema de Corte de Estoque Unidimensional}

O problema de corte de estoque unidimensional pode ser definido da seguinte forma:

Considere um número grande de peças (como por exemplo rolos de papel - bobinas, canos(PVC)) de um determinado comprimento L, que chamamos de objetos, e um conjunto de pedidos, com demanda $b_{i}, i=1, \cdots, m$ de barras menores de comprimentos $l_{i}, \quad i=1, \cdots, m$, os quais chamamos de itens $\left(l_{i} \leq L\right)$. O problema então consiste em produzir os itens a partir do corte de peças em estoque de modo a atender a demanda, otimizando uma certa função, por exemplo, minimizar o número total de peças a serem cortadas, ou minimizar a perda, ou maximizar o lucro, satisfazendo a demanda.

\subsubsection{Modelo Inicial}

Por simplicidade, considere inicialmente apenas um tipo de barra em estoque. Assim, a seguir, o problema de corte de estoque unidimensional sera modelado.

(a)
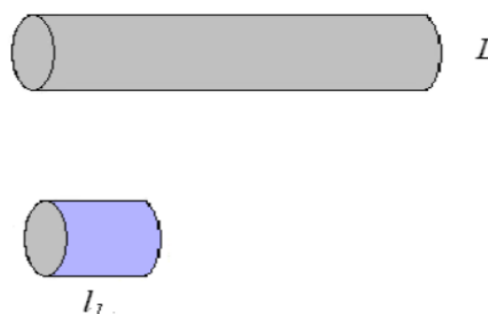

(b)

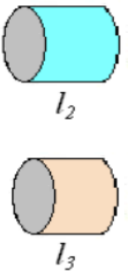

padrăo 1

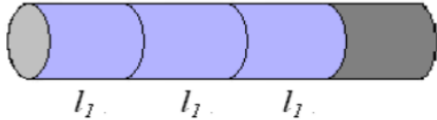

padrão 2

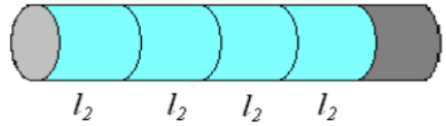

(c)

padrằ 3

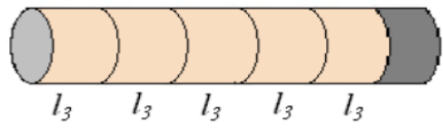

padrăo 4

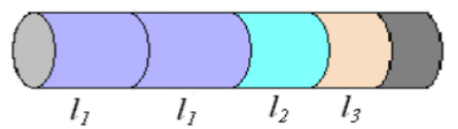

padrẫo 5

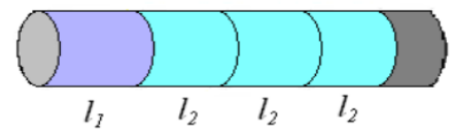

Figura 2.1: (a) Objeto a ser cortado; (b) itens demandados; (c) exemplos de padrões de corte.

Para cortar a peça de tamanho $L$, definimos um padrão de corte, que consiste numa maneira particular de se cortar um objeto representado por um vetor $a^{T}=\left(a_{1}, a_{2}, \cdots, a_{m}\right)^{T}$, isto é, $a_{1}$ quantidade de peças de tamanho $l_{1}, a_{2}$ quantidade de peças de tamanho $l_{2}$, e assim sucessivamente. Veja a Figura (2.1(c)), e, sempre que dois padrões de corte tiverem 
o mesmo vetor associado são equivalentes. Existe um número finito de padrões de corte, que é muito grande para exemplos reais que utilizam dezenas ou centenas de itens.

Um vetor $a^{T}=\left(a_{1}, a_{2}, \cdots, a_{m}\right)^{T}$ corresponde a um padrão de corte se e somente se satisfizer as restrições do Problema da Mochila (considerando apenas as restrições físicas), podemos ver exemplos na Figura (2.1):

$$
\begin{aligned}
& l_{1} a_{1}+l_{2} a_{2}+\cdots+l_{m} a_{m} \leq L \\
& a_{i} \geq 0 \text { e inteiro, } \quad i=1,2, \cdots, m
\end{aligned}
$$

Outras restrições de processo (por exemplo, limitação no número de facas) podem ser incluídas em (2.1).

Definição 2.1 Um padrão de corte que produza apenas um tipo de item é chamado padrão de corte homogêneo

Em outras palavras, um padrão de corte é homogêneo se o vetor associado tem apenas uma coordenada não-nula: $\left(0, \cdots, a_{i}, \cdots, 0\right)^{T}, a_{i} \neq 0$. Os padrões 1,2 e 3 da Figura (2.1) são exemplos de padrões de corte homogêneo. Note que sempre teremos $m$ padrões homogêneos, cujos vetores associados definem uma matriz diagonal. A hipótese de que $\ell_{i} \leq L$, para todo $i$, está implícita, caso contrário o problema seria infactível, sendo que os valores $a_{i}$ são determinados por $a_{i}=\left\lfloor\frac{L}{\ell_{i}}\right\rfloor i=1, \cdots, m$.

Após definirmos os padrões de corte, o próximo passo será determinar o número de vezes que cada padrão será utilizado para atender a demanda, ou seja, a modelagem matemática de um problema de corte de estoque é feita em duas etapas:

1. Definir todos os possíveis padrões de corte (supondo $n$ o número total de padrões obtidos);

$$
a_{1}=\left(\begin{array}{c}
a_{11} \\
a_{21} \\
\vdots \\
a_{m 1}
\end{array}\right) \quad, a_{2}=\left(\begin{array}{c}
a_{12} \\
a_{22} \\
\vdots \\
a_{m 2}
\end{array}\right), \ldots, \quad a_{n}=\left(\begin{array}{c}
a_{1 n} \\
a_{2 n} \\
\vdots \\
a_{m n}
\end{array}\right)
$$


2. Definir quantas vezes cada padrão de corte será utilizado para atender a demanda, que deverá ser um número inteiro e não-negativo.

Seja $x_{j}$ : o número de vezes que o objeto é cortado usando o padrão $j$.

Supondo que o total de barras cortadas deva ser minimizado, o problema de corte de estoque pode ser modelado por:

$$
\begin{array}{ll}
\text { minimizar } & f(x)=\sum_{j=1}^{n} x_{j} \\
\text { sujeito } a:\left\{\begin{array}{l}
\sum_{j=1}^{n} a_{j} x_{j}=b \\
x_{j} \geq 0 \text { e inteiro }
\end{array}\right.
\end{array}
$$

sendo que cada coluna da matriz de restrições é um vetor associado a um padrão de corte.

A função objetivo em (2.2) minimiza o total de objetos a serem cortados. As primeiras restrições em (2.2) garantem que a quantidade de itens produzidos é exatamente igual à demanda e as últimas restrições em (2.2) garantem que a repetição de cada padrão de corte $j$ é um número inteiro não-negativo.

Ainda podemos considerar outros objetivos como, por exemplo, minimizar a perda total. Neste caso, a função objetivo em (2.2) seria substituída pela função perda total, que é definida como:

$$
f(x)=\sum_{j=1}^{n} c_{j} x_{j}
$$

em que

$$
c_{j}=L-\left(a_{1 j} \ell_{1}+a_{2 j} \ell_{2}+\cdots+a_{m j} \ell_{m}\right)
$$

define a perda no padrão de corte $j, j=1, \cdots, n$

A minimização da função $f(\mathbf{x})$ em (2.3) resulta no conjunto de padrões de corte com perda mínima. Observamos que, neste caso simples, em que há apenas um tipo de objeto em estoque, são equivalentes: minimizar o total de objetos cortados e minimizar a perda total. A prova desta afirmação segue no apêndice B.

A condição de integralidade sobre as variáveis $x_{j}$ torna o problema de corte $(2.2)$ difícil, senão impossível, de ser resolvido computacionalmente. Para contornar este pro- 
blema relaxamos a condição de integralidade sobre as variáveis $x_{j}$ e resolvemos o problema de otimização linear resultante pelo Método Simplex. Em problemas grandes, o número de itens $m$ é da ordem de dezenas, enquanto que $n$ o qual depende de $m, L \quad e \ell_{i}, i=1, \ldots, m$ pode ser da ordem de milhões, o que inviabiliza a resolução direta do problema. Para contornar esta dificuldade, utilizamos o processo de geração de colunas na resolução da relaxação por otimização linear de (2.2). Arredondamentos heurísticos podem ser desenvolvidos para a obtenção de soluções inteiras (Wäscher e Gau; 1996, Poldi 2003), restando um problema residual de baixa demanda, que Poldi (2003) mostrou que também pode ser resolvido eficientemente pelo mesmo modelo linear.

\subsubsection{Modelagem dos problemas com vários tipos de barras em estoque em quantidades limitadas}

No modelo anterior foram considerados apenas os dados dos itens (comprimentos e demandas) e apenas um tipo de barra em estoque. Apresentamos agora um modelo no qual temos vários tipos de barras em estoque e em quantidades limitadas, proposto por Gilmore e Gomory [5]. Devemos considerar os seguintes dados:

\section{Dados de Entrada:}

- $m$ : número de tipos de itens;

- $\ell_{i}$ dimensão do item $i, i=1, \ldots, m$;

- $d_{i}$ : demanda do item tipo $i, i=1, \ldots, m$.

\section{Dados de estoque:}

- K : número de tipos de objetos em estoque;

- $L_{k}$ dimensão do objeto $k, k=1, \ldots, K$

- $c_{k}$ : custo do objeto $k, k=1, \ldots, K$

- $e_{k}$ : disponibilidade em estoque do objeto $k, k=1, \cdots, K$

O modelo matemático é análogo ao caso anterior, entretanto, os padrões de corte devem ser definidos para cada tipo de barra em estoque, isto é, devem satisfazer, para cada $k, k=1, \cdots, K$ : 


$$
\begin{aligned}
& \ell_{1} a_{1 k}+\ell_{2} a_{2 k}+\cdots+\ell_{m} a_{m k} \leq L_{k} \\
& a_{i k} \geq 0 \text { e inteiro, } i=1,2, \cdots, m .
\end{aligned}
$$

Suponha que o sistema (2.4) tenha $N_{k}$ soluções, dadas por:

$$
a_{1 k}=\left(\begin{array}{c}
a_{11 k} \\
a_{21 k} \\
\vdots \\
a_{m 1 k}
\end{array}\right), a_{2 k}=\left(\begin{array}{c}
a_{12 k} \\
a_{22 k} \\
\vdots \\
a_{m 2 k}
\end{array}\right) \quad, \ldots a_{N_{k} k}=\left(\begin{array}{c}
a_{1 N_{k} k} \\
a_{2 N_{k} k} \\
\vdots \\
a_{m N_{k} k}
\end{array}\right), k=1, \cdots, K
$$

sendo que $a_{i j k}$ é o número de itens do tipo do tipo $i$ no padrão de corte $j$ para o objeto $k, i=1, \cdots, m, j=1, \cdots, N_{k}, k=1, \cdots, K$ ( $\mathbf{a}_{\mathbf{j k}}$ é o vetor correspondente ao $j$-ésimo padrão de corte para o objeto $\mathbf{k}$ )

O custo do objeto $k, c_{k}$, pode ser a perda produzido pelo padrão de corte $j$ e neste caso:

$$
c_{j k}=L_{k}-\sum_{i=1}^{m}\left(\ell_{i}-a_{i j k}\right)
$$

Algumas vezes, minimizar o custo é mais interessante do que minimizar a perda, pois os objetos podem ser comprados com descontos (por ter dimensões fora dos padrões), ou são retalhos de cortes anteriores que retornaram ao estoque e deseja-se que estes sejam utilizados antes que os outros objetos.

\section{Variável de decisão:}

- $x_{j k}$ : número de objetos do tipo $k$ cortados segundo o padrão $j, j=1, \cdots, N_{k}$, $k=1, \cdots, K$.

O problema pode então ser formulado por: 


$$
\begin{aligned}
& \text { minimizar } f\left(x_{11}, x_{12}, \cdots, x_{N_{k} k}\right)=\sum_{j=1}^{N_{1}} c_{1} x_{j 1}+\sum_{j=1}^{N_{2}} c_{2} x_{j 2}+\cdots+\sum_{j=1}^{N_{k}} c_{K} x_{j K}
\end{aligned}
$$

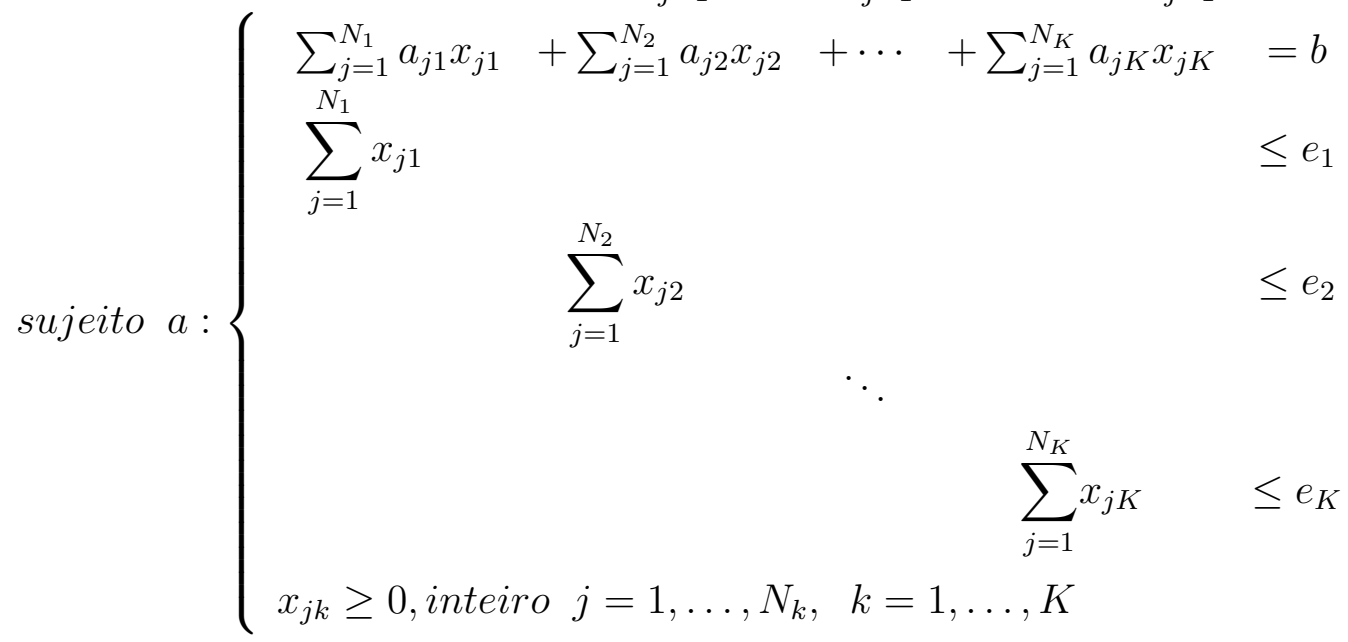

O modelo básico (2.2), com um único tipo de objeto em estoque, é apenas um caso particular deste modelo (2.5) com $K=1$ e $e_{1}$ não limitado. As colunas da matriz de restrições são os vetores associados aos padrões de corte para cada objeto, agora complementando com $K$ componentes com 1 na posição $(m+k)$ e 0 nas demais. Assim, uma coluna $j$ do modelo (2.5) pode ser escrita como em (2.6):

$$
\left(\begin{array}{c}
a_{i j k} \\
\vdots \\
a_{m j k} \\
0 \\
\vdots \\
1 \\
\vdots \\
0
\end{array}\right)
$$

A primeira linha de restrições do modelo (2.5) garante que a quantidade de itens produzidos seja exatamente igual à demanda. As outras restrições $(\leq)$ garantem que a quantidade de cada barra disponível em estoque não seja violada e a última restrição garante que a repetição de cada padrão de corte $j$ seja um número inteiro não-negativo. 
Dependendo da aplicação em estudo, diferentes regras são usadas para definição de um padrão de corte, tais como, limitação de itens, estágios, etc. Por exemplo, nas indústrias papeleira ou metalúrgica, bobinas são cortadas e é comum que o número de facas disponíveis ser limitado, produzindo com isto limitações no padrão de corte. 


\section{Capítulo 3}

\section{Revisão Bibliográfica Específica}

Marsten [10] propôs o método BOXSTEP, no qual as variáveis duais são restritas a uma caixa centrada na solução anterior. Lubbecke [9] propõe um novo limitante para a programação dinâmica utilizando o processo de geração de colunas, sendo que este limitante é encontrado restringindo as variáveis duais a valores positivos. Recentemente Bem Amor e Desrodiers [3] sugeriram um método de penalização, o qual estende o método de Boxstep de Marsten, utilizando uma função que define o valor das variáveis duais para 5 intervalos distintos para o problema de corte de estoque. Tentando estabilizar o processo de geração de colunas Merle et al. [10] apresentaram um processo de estabilização, o qual combina um método de perturbação e um método de penalização exato (que penaliza as variáveis duais caso assumam valores fora de caixas pré determinadas). Utilizando outra estratégia de estabilização e aceleração Valério de Carvalho [13] e Amor [2] restringem o espaço dual. Esse método, já considerado por Gilmore e Gomory [4] em (1961), consiste em restringir o espaço dual de modo a evitar bruscas variações (instabilidade) nas soluções duais, objetivando acelerar o processo de geração de colunas.

\subsection{Processo de Geração de Colunas e o espaço dual}

Consideremos um problema primal com um número muito grande de colunas, que resolveremos pelo método Simplex com geração de colunas e seu problema dual. O problema primal é uma relaxação do problema de corte de estoque, em que as colunas são padrões de corte válidos. Como função objetivo minimizamos o número de objetos cor- 
tados, portanto $c=(1, \ldots, 1)^{T}$.

Primal: Dual:

$$
\begin{array}{lr}
\text { Min } f(x)=c^{T} x & \text { Max } g(x)=b^{T} \pi . \\
\text { s.a. }\left\{\begin{array}{cc}
A x=b & \text { s.a. }\left\{\begin{array}{c}
A^{T} \pi \leq c \\
\pi \text { irrestrito }
\end{array}\right.
\end{array}\right.
\end{array}
$$

Cada coluna do problema primal, ou seja, um padrão de corte do problema de corte de estoque, corresponde a uma restrição no espaço dual, de modo que podemos descrever o método de geração de colunas da seguinte forma:

- Usar um conjunto de colunas primais, ou restrições duais para iniciar o problema;

- A cada iteração, novas restrições duais são inseridas no modelo eliminando soluções duais infactíveis;

- O espaço dual é iterativamente restringido até encontrarmos a solução ótima.

Podemos ver na Figura (3.1) como o método de geração de colunas se comporta no espaço dual. Um conjunto de colunas (padrões de corte), inicialmente aproxima o espaço dual, o que é representado pelas restrições 1 e 2, com as quais a solução ótima é o ponto (A). Geramos um novo padrão de corte, ou seja, uma nova restrição dual 3, e obtemos a nova solução (B) determinada pelas restrições 2 e 3 (a restrição fica inativa no dual, que significa no primal que a coluna correspondente sai da base). Iteramos mais uma vez gerando a restrição 4, que aliada á restrição 3 determina a solução (C) e, por fim, geramos a quinta restrição, que aliada à restrição 4 determina a solução ótima (D). Observe que as restrições 1 e 2, que fornecem limitantes superiores para as variáveis duais: $\pi_{i} \leq u_{i}$ são típicas em problemas de corte por causa dos padrões homogêneos. Além disso, como $b>0$ (demanda dos itens) então a solução ótima dual é sempre não negativa.

Assim, se considerarmos no problema dual a restrição $\pi>0$, isto não perde a otimalidade do problema primal (apesar do dual ser mais restrito) e é equivalente a considerar o problema primal como $A x \geq b$. Retomaremos esta observação na próxima seção. 


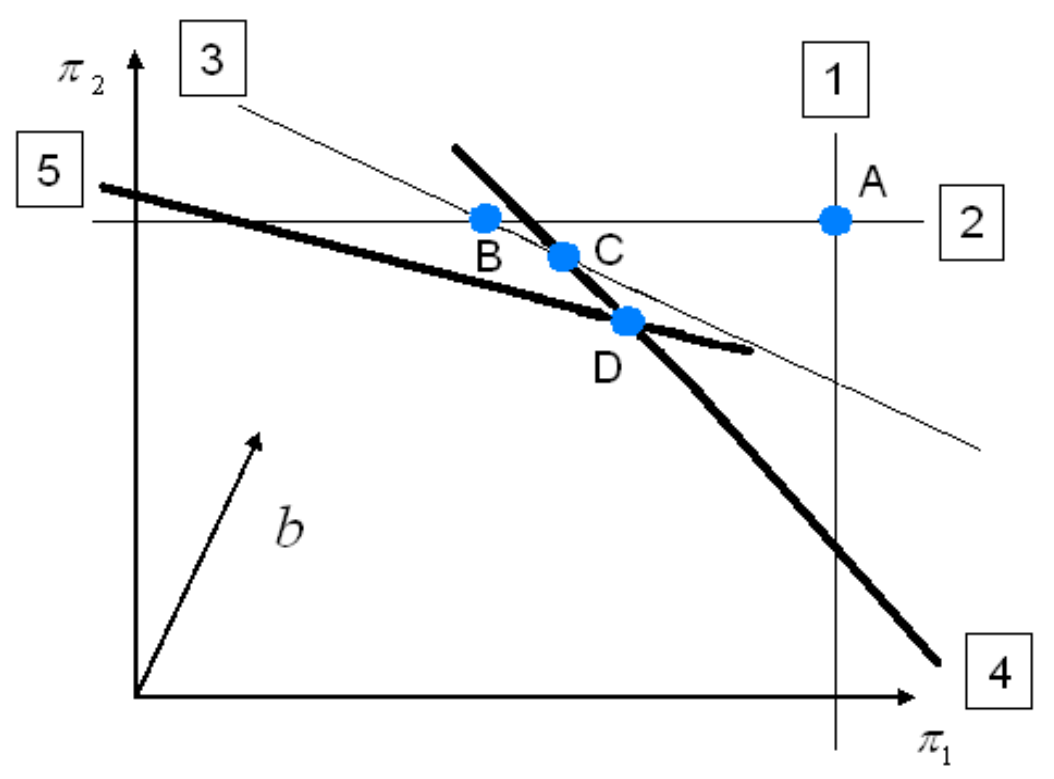

Figura 3.1: Geração de colunas no espaço dual.

\subsection{Cortes Duais}

A utilização de um espaço dual mais restrito desde o início do processo de geração de colunas pode auxiliar a encontrar a solução ótima mais rapidamente e a melhorar a degeneração primal. Muitos pesquisadores obtiveram processos de geração de colunas mais rápidos e estáveis quando utilizaram restrições mais fortes no espaço dual. Por exemplo, podemos substituir as restrições de igualdade por desigualdades de maior ou igual no problema primal restrito, o que induz a não negatividade sobre as variáveis duais. Isto foi feito por Gilmore e Gomory [4] no problema de corte, sob o argumento de que: dada qualquer solução ótima com folga, existe uma solução alternativa sem folga. Considere o problema primal acrescido de novas colunas e seu dual.

$$
\begin{aligned}
& \text { Min } f(x)=c^{T} x+d^{T} y \quad \text { Max } g(\pi)=b^{T} \pi \\
& \text { s.a. }\left\{\begin{array} { c } 
{ A x + D y = b } \\
{ x \geq 0 , y \geq 0 }
\end{array} \Leftrightarrow \quad \text { s.a. } \left\{\begin{array}{c}
A^{T} \pi \leq c \\
D^{T} \pi \leq d \\
\pi \text { irrestrito }
\end{array}\right.\right.
\end{aligned}
$$

Se a matriz $D=-I$ e $d=0$ (caso considerado por Gilmore e Gomory) o problema que equivale a considerar as restrições primais: $A x \geq b$, então o dual é: $A^{T} \pi \leq c$ e $\pi \geq 0$.

Estas inequações são cortes duais válidos para o problema de corte, porque existem 
sempre soluções duais ótimas não-negativas. O interessante é que as condições de nãonegatividade sobre as variáveis duais estão presente durante todo o processo de geração de colunas. Desta forma não haverá em nenhuma iteração variáveis duais negativas, logo a restrição do espaço dual reduz o número de colunas possíveis que o subproblema pode propor ao problema primal restrito e certas colunas nunca serão geradas, melhorando assim a convergência. Em relação à degeneração, a restrição dual pode reduzir o número de soluções básicas que correspondem a um ponto extremo degenerado.

Exploraremos agora a idéia de adicionar restrições duais extras ao modelo, antes de iniciar o processo de geração de colunas, correspondendo a inserir novas variáveis no problema primal que serão nulas em alguma solução ótima. Isto faz restringir o espaço dual com adição de novas restrições $D^{T} \pi \leq d$, enquanto que a inserção de novas colunas no problema primal relaxa o espaço primal.

\subsubsection{Uma Família de cortes duais para os itens}

Valério de Carvalho [13] propôs a construção de cortes duais usando a seguinte estratégia. Suponha que um item $i$ satisfaça:

$$
\sum_{s \in S} \ell_{s} \leq \ell_{i}
$$

isto é, o comprimento do item $i$ é maior do que a soma dos comprimentos dos itens no conjunto S, então a seguinte restrição chamada corte dual pode ser incluída no problema dual, sem perda de solução ótima:

$$
-\pi_{i}+\sum_{s \in S} \pi_{s} \leq 0
$$

Para cada $i$ podemos definir diferentes conjuntos $S$, de modo que (3.2) define uma família de cortes duais. Devido a dificuldade de gerar, para cada $i$, todos os conjuntos $S$ com a propriedade (3.1), Valério de Carvalho limita o conjunto $S$ a casos mais simples, por exemplo, conjuntos unitários: $S=\{j\}$, ou seja, $\ell_{j} \leq \ell_{i}$ e (3.2) é dado por $-\pi_{i}+\pi_{j} \leq 0$. Isto produz uma coluna, em que o -1 está na $i$-ésima linha e o 1 aparece na $j$-ésima linha, no problema primal da forma: 


$$
\left(\begin{array}{c}
0 \\
\vdots \\
-1 \\
\vdots \\
1 \\
0
\end{array}\right)
$$

Estas restrições são inseridas no problema dual criando o problema "dual estendido". O respectivo problema primal, chamado "primal estendido", pode ser resolvido por geração de colunas. A base ótima será da forma:

$$
\left[\begin{array}{cccccc}
a_{11} & \ldots & a_{1 p} & 0 & \ldots & 0 \\
a_{21} & \ldots & a_{2 p} & -1 & \ldots & 0 \\
\vdots & \ldots & \vdots & 1 & \ldots & -1 \\
a_{m 1} & \ldots & a_{m p} & 0 & \ldots & 1
\end{array}\right]
$$

isto é, as $p$ primeiras colunas são padrões de corte e as $(n-p)$ últimas colunas são de cortes introduzidos.

\subsubsection{Uma nova interpretação dos cortes duais para os itens}

Por simplicidade, consideramos um corte dual simples (seção 3.2.1) da seguinte forma. Seja o item $i$ e o conjunto unitário $S=\{j\}\left(\ell_{j} \leq \ell_{i}\right)$ e o corte dual:

$$
-\pi_{i}+\pi_{j} \leq 0
$$

Para o caso em que $S$ não é unitário, o desenvolvimento a seguir é estendido analogamente.

Seja o padrão de corte repreentado por $a_{1}=\left(a_{11}, \ldots, a_{i 1}, \ldots, a_{j 1}, \ldots, a_{m 1}\right)$ e suponha que $a_{i 1}>0$ (i. é., o item de índice $i$ é cortado $a_{i 1}$ vezes neste padrão). Podemos construir um novo padrão de corte substituindo os itens de índice $i$ ( $a_{i 1}$ vezes) por itens de índice $j$ (já que $l_{j} \leq l_{i}$ ) o qual tem a seguinte coluna associada: $a_{2}=\left(a_{11}, \ldots, 0, \ldots, a_{i 1}+a_{j 1}, \ldots, a_{m 1}\right)$.

Observe que: 


$$
a_{2}-a_{1}=\left(\begin{array}{c}
0 \\
\vdots \\
-a_{i 1} \\
+a_{i 1} \\
\vdots \\
0
\end{array}\right)=a_{i 1}\left(\begin{array}{c}
0 \\
\vdots \\
-1 \\
1 \\
\vdots \\
0
\end{array}\right)=a_{i 1} d_{1}
$$

Os elementos (-1) e (+1) estão nas posições $i$ e $j$, respectivamente. Assim, $d_{1}=(0, \ldots,-1, \ldots,+1, \ldots, 0)^{T}$ é exatamente a coluna associada ao corte dual de Valério de Carvalho. Podemos interpretar os cortes duais como operações elementares (subtração entre colunas) nas colunas da matriz A, o que corresponde a uma mudança de variável (uma nova variável surge para a nova coluna). Estas novas colunas (decorrentes dos corte duais) podem ser geradas a priore, sem a necessidade de se conhecer os padrões, como Valério de Carvalho percebeu. Esta nova interpretação nos permite definir novas famílias de cortes ( seção 3.2.4)

\subsubsection{Recuperando a solução do problema primal}

Tendo a solução ótima do problema primal estendido, a qual pode conter colunas associadas aos cortes duais:

$$
a_{1} x_{1}+\cdots+a_{p} x_{p}+d_{1} y_{1}+\cdots+d_{r} y_{r}=b
$$

desejamos encontrar uma solução do problema primal, na qual as variáveis associadas aos cortes duais são nulas:

$$
a_{1} x_{1}^{\prime}+a_{2} x_{2}^{\prime}+\ldots+a_{p} x_{p}^{\prime}+a_{p+1} x_{p+1}^{\prime}+\cdots=b
$$

Possivelmente outros padrões de corte serão necessários: $a_{p+1}, \ldots$ Para iniciar o processo tomamos o primeiro corte dual escolhido lexicograficamente, ou seja, cortes duais que possuem $(-1)$ na linha de menor índice estão em primeiro, e em seguida escolhemos aleatoriamente um padrão de corte que possui itens na mesma linha referente a linha do 
corte dual que possui o $(-1)$. Sem perda de generalidade, suponha que seja o primeiro padrão de corte e o primeiro corte dual, com isso temos a seguinte igualdade.

$$
a_{1} x_{1}+d_{1} y_{1}=b^{\prime}
$$

representado na Figura (3.2).

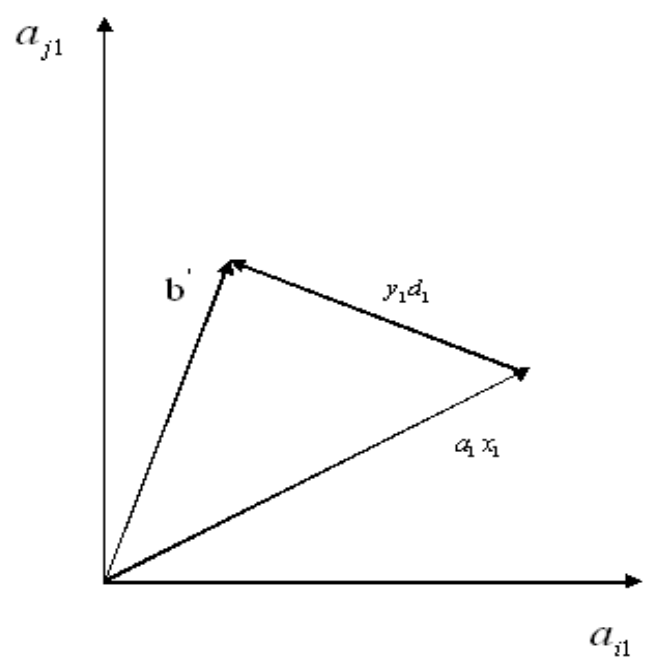

Figura 3.2: Combinação linear de $b^{\prime}$.

Primeiramente substituímos na solução 3.7 o corte dual $d_{1}=\frac{1}{a_{i 1}}\left(a_{2}-a_{1}\right)$ encontrando o seguinte:

$$
a_{1} x_{1}+\left(\frac{y_{1}}{a_{i 1}} a_{2}-a_{1} \frac{y_{1}}{a_{i 1}}\right)=b^{\prime}
$$

Observe que o vetor $a_{2}=\left(a_{11}, \ldots, 0, \ldots, a_{i 1}+a_{j 1}, \ldots, a_{m 1}\right)$ foi criado a partir de uma padrão de corte $a_{1}=\left(a_{11}, \ldots, a_{i 1}, \ldots, a_{j 1}, \ldots, a_{m 1}\right)$ sendo que podemos substituir os itens $i$ ( $a_{i 1}$ vezes) por itens $j$, que foi mostrado na seção (3.2.2).

Organizando a equação 3.8 temos;

$$
a_{1}\left(x_{1}-\frac{y_{1}}{a_{i 1}}\right)+a_{2} \frac{y_{1}}{a_{i 1}}=b^{\prime}
$$

representado na Figura (3.3). 


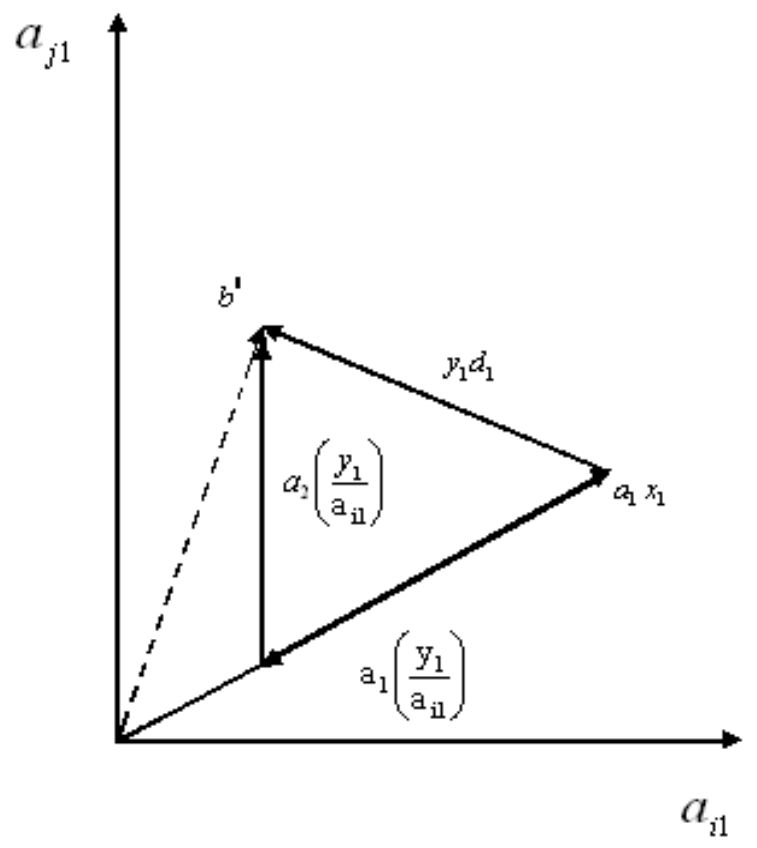

Figura 3.3: Combinação linear de $b^{\prime}$.

Para que a nova solução seja factível devemos ter:

$$
\left(x_{1}-\frac{y_{1}}{a_{i 1}}\right) \geq 0
$$

Caso isso aconteça, seguindo as atribuições abaixo, encontramos uma solução do problema primal, na qual o corte dual é eliminado. Desta forma selecionamos outro corte dual e outro padrão de corte, e repetimos a substituição de variáveis com o intuito de eliminarmos todas as varáveis associadas aos cortes duais.

$$
x_{1}^{\prime}=x_{1}-\frac{y_{1}}{a_{i 1}} \quad x_{2}^{\prime}=\frac{y_{1}}{a_{i 1}}
$$

Portanto temos a solução do problema primal

$$
a_{1} x_{1}^{\prime}+a_{2} x_{2}^{\prime}=b^{\prime}
$$

representado na Figura (3.4). 


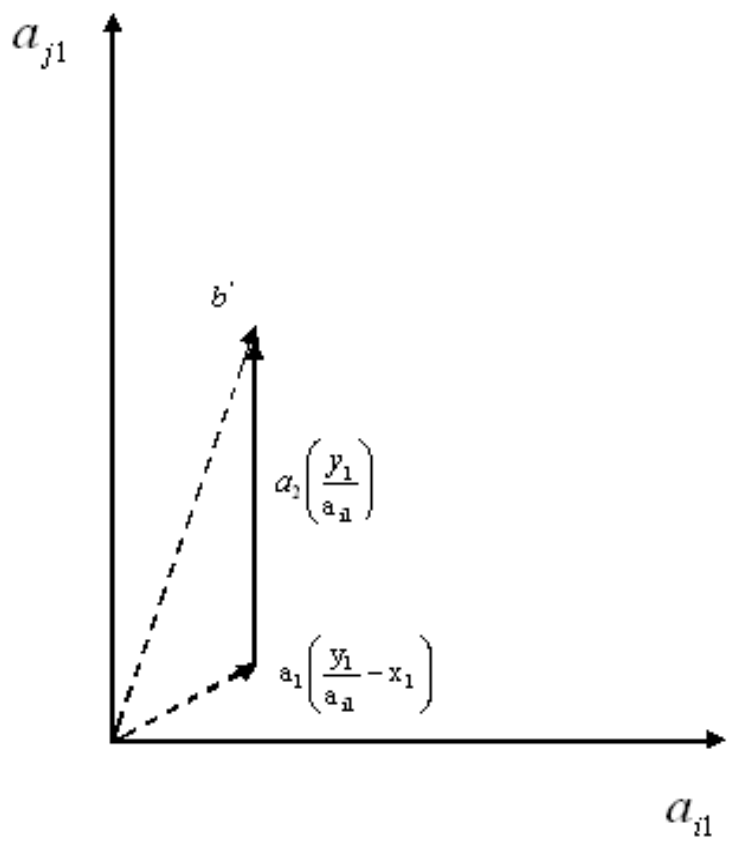

Figura 3.4: Combinação linear de $b^{\prime}$.

Caso a desigualdade 3.10 não seja obedecida $b^{\prime}$ é escrito como combinação linear positiva de $d_{1}$ e $a_{2}$ como podemos ver na Figura (3.5) abaixo.

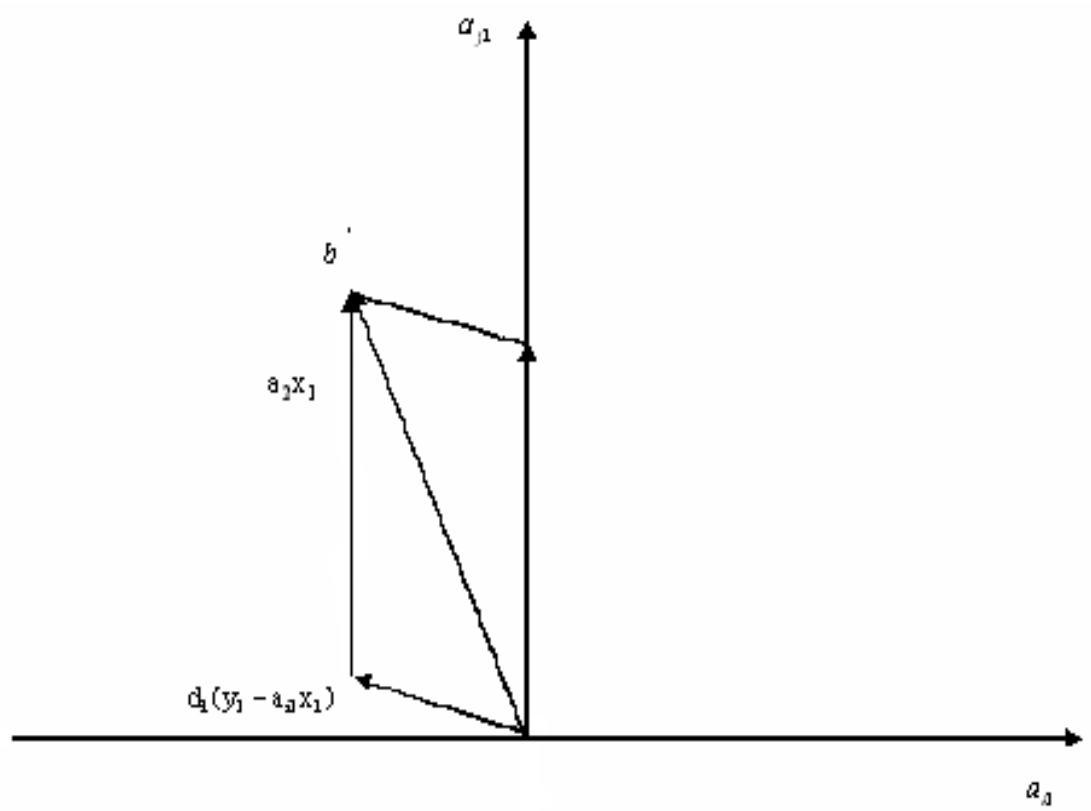

Figura 3.5: Combinação linear de b'.

Em relação aos itens isto significa que o corte dual $d_{1}$ deve cortar mais peças que o padrão de corte $a_{1}$ fornece, assim o padrão de corte $a_{1}$ não será mais utilizado e o valor 
da variável relativa ao corte dual $d_{1}$ decresce gerando a solução abaixo.

$$
d_{1}\left(y_{1}-x_{1} a_{i 1}\right)+a_{2} x_{1}=b^{\prime}
$$

Como o corte dual permanece na solução selecionamos outro padrão de corte e repetimos a substituição de variáveis com o intuito de eliminarmos todas as varáveis associadas aos cortes duais. Ao introduzir os cortes duais durante todo o processo da geração de colunas evitamos que mochilas sejam geradas acelerando o processo, pois os padrões já estão implicitamente na solução e são recuperados ao aplicarmos o processo acima descrito. Como os cortes duais restringem o espaço dual, menos pontos estão disponíveis para o método de geração de colunas testar, evitando grandes oscilações das variáveis duais tentando assim estabilizá-lo. A quantidade de cada item não se altera durante a recuperação da solução, bem como o valor da função objetivo como podemos ver abaixo.

Para mostrar que as quantidades produzidas de itens não se alteram, considere sem perda de generalidade que utilizamos o $i$-ésimo item para cortar o $(i+1)$-ésimo item (caso que $|S|=1$ e $s_{1}=i+1$ ). Tomemos a seguinte coluna (padrão de corte) e o corte dual abaixo:

$$
\cdots x_{j}\left(\begin{array}{c}
a_{1 j} \\
\vdots \\
a_{i j} \\
a_{i+1, j} \\
\vdots \\
a_{m j}
\end{array}\right)+y_{r}\left(\begin{array}{c}
0 \\
\vdots \\
-1 \\
1 \\
\vdots \\
0
\end{array}\right)+\cdots=\left(\begin{array}{c}
b_{1} \\
\vdots \\
b_{i} \\
b_{i+1} \\
\vdots \\
b_{m}
\end{array}\right)
$$

Observemos que o item na linha respectiva a linha que contém o $(-1)$ no corte dual deve ser positivo $a_{i j}>0$. Mostramos que podemos diminuir o valor de $y_{r}$ apenas alterando o padrão $j$ e sua freqüência, os demais padrões e suas freqüências $x_{j}$ ficam inalterados. Assim, as equações $i$ e $(i+1)$ são dadas por:

$$
\cdots+x_{j} a_{i j}-y_{r}+\cdots=b_{i}
$$




$$
\cdots+x_{j} a_{i+1, j}+y_{r}+\cdots=b_{i+1}
$$

Se $y_{r}-x_{j} a_{i j} \geq 0$ :

As colunas e variáveis seriam modificadas da seguinte forma:

$$
\cdots+x_{j}^{\prime}\left(\begin{array}{c}
a_{1 j} \\
\vdots \\
0 \\
a_{i j}+a_{i+1, j} \\
\vdots \\
a_{m j}
\end{array}\right)+y_{r}^{\prime}\left(\begin{array}{c}
0 \\
\vdots \\
-1 \\
1 \\
\vdots \\
0
\end{array}\right)+\cdots
$$

sendo que:

- $x_{j}^{\prime}=x_{j}$

- $y_{r}^{\prime}=y_{r}-x_{j} a_{i j}$;

- $x_{j}=0$.

Deste modo, apenas as quantidades produzidas dos itens $i$ e $(i+1)$ poderiam ser afetadas. Mostremos agora que não são afetadas.

A coordenada $i$ de (3.15) é dada por:

$\cdots+x_{j}^{\prime} .0-y_{r}^{\prime} \cdots=\cdots-y_{r}+x_{j} a_{i j} \cdots=b_{i}$

A última igualdade decorre de (3.13)

A componente $i+1$ de (3.15)

$$
\begin{aligned}
& \cdots x_{j}^{\prime} \cdot\left(a_{i j}+a_{i+1 j}\right)+y_{r}^{\prime}+\cdots=\cdots+x_{j} a_{i j}+x_{j} a_{i+1 j}+y_{r}-x_{j} a_{i j}+\cdots=\cdots+y_{r}+ \\
& x_{j} a_{i+1 j}+\cdots=b_{i+1}
\end{aligned}
$$

A última igualdade decorre de (3.14)

Mostraremos agora que a função objetivo fica inalterada para as duas soluções.

$f(x)=\cdots+c_{j} x_{j}+\cdots$, inicialmente.

$f\left(x^{\prime}\right)=\cdots+c_{j}^{\prime} x_{j}^{\prime}+\cdots$ 
Como $c_{j}=1$ para todos padrões de corte e $x_{j}^{\prime}=x_{j}$ então $f(x)=f\left(x^{\prime}\right)$, portanto, $x^{\prime}$ é também uma solução ótima. Podemos observar que o valor da variável relativa ao corte dual decresceu de valor, neste caso selecionamos outros padrões de corte enquanto $y_{r}$ for positiva.

Se $y_{r}-x_{j} a_{i j}<0$

As colunas e variáveis seriam modificadas da seguinte forma:

$$
\cdots+x_{j}^{\prime \prime}\left(\begin{array}{c}
a_{1 j} \\
\vdots \\
0 \\
a_{i j}+a_{i+1 j} \\
\vdots \\
a_{1 m}
\end{array}\right)+x_{j}^{\prime}\left(\begin{array}{c}
a_{1 j} \\
\vdots \\
a_{i j} \\
a_{i+1 j} \\
\vdots \\
a_{1 m}
\end{array}\right)+y_{r}\left(\begin{array}{c}
0 \\
\vdots \\
-1 \\
1 \\
\vdots \\
0
\end{array}\right)+\cdots
$$

sendo que:

- $x_{j}^{\prime \prime}=\frac{y_{r}}{a_{i j}} ;$

- $x_{j}^{\prime}=x_{j}-\frac{y_{r}}{a_{i j}}$

- $y_{r}=0$.

Deste modo, apenas as quantidades dos itens $i$ e $(i+1)$ poderiam ser afetadas. Mostremos agora que não são afetadas.

A coordenada $i$ de (3.16) é dada por:

$\cdots+x_{j}^{\prime \prime} .0+x_{j}^{\prime} a_{i j}+\cdots=\cdots+\left(x_{j}-\frac{y_{r}}{a_{i j}}\right) a_{i j}+\cdots=\cdots+x_{j} a_{i j}-y_{r}+\cdots=b_{i}$

A última igualdade decorre de (3.13)

A componente $i+1$ de (3.16)

$\cdots+x_{j}^{\prime \prime} \cdot\left(a_{i j}+a_{i+1 j}\right)+x_{j}^{\prime} a_{i+1 j}+\cdots=\cdots+\frac{y_{r}}{a_{i j}} a_{i j}+\frac{y_{r}}{a_{i j}} a_{i+1 j}+\left(x_{j}-\frac{y_{r}}{a_{i j}}\right) a_{i+1 j}+\cdots$
$=\cdots+x_{j} a_{i+1}+y_{r}+\cdots=b_{i+1}$

A última igualdade decorre de (3.14)

Mostraremos agora que a função objetivo fica inalterada para as duas soluções. 
$f(x)=\cdots+c_{j} x_{j}+\cdots$, inicialmente.

$f\left(x^{\prime \prime}\right)=+\cdots+c_{j}^{\prime \prime}\left(x_{j}^{\prime \prime}+x_{j}^{\prime}\right)+\cdots=\cdots+c_{j}^{\prime \prime}\left(\frac{y_{r}}{a_{i j}}+x_{j}-\frac{y_{r}}{a_{i j}}\right)+\cdots=\cdots+c_{j}^{\prime \prime} x_{j}+$

Como $c_{j}=1$ para todos padrões de corte, então $f(x)=f\left(x^{\prime \prime}\right)$, portanto, $x^{\prime \prime}$ é também uma solução ótima. Podemos observar que neste caso a variável relativa ao corte dual foi anulada. Então é sempre possível encontrar uma solução ótima sem os cortes duais.

\subsubsection{Proposta para uma nova família de cortes duais}

Uma família de cortes duais é proposta e se baseia em extensões dos cortes básicos propostos por Valério de Carvalho.

Corte básico: conjunto $S$ tal que $\sum_{s \in S} \ell_{s} \leq \ell_{i} \Rightarrow-\pi_{i}+\sum_{s \in S} \pi_{s} \leq 0$.

Corte estendido: conjunto $S$ tal que $\sum_{s \in S} \beta_{s} \ell_{s} \leq \ell_{i} \Rightarrow-\pi_{i}+\sum_{s \in S} \beta_{s} \pi_{s} \leq$ $0, \beta_{s}>0$ e inteiro.

Consideramos $S=\{j\}$, assim utilizamos $\beta_{j}=\left\lfloor\frac{\ell_{i}}{\ell_{j}}\right\rfloor$ para representar a quantidade inteira positiva que um item maior pode ser utilizado para substituir um item menor.

Veremos em um exemplo, em que $|S|=\{1\}$ e $S=\{2\}$, como ambos os cortes se comportam:

Consideremos dois itens $\ell_{1}=10$ e $\ell_{2}=4$.

As desigualdades de Valério de Carvalho são : $-\pi_{1}+\pi_{2} \leq 0(4 \leq 10)$.

As desigualdades relativas aos cortes estendidos são : $-\pi_{1}+2 \pi_{2} \leq 0(2 * 4 \leq 10)$.

Nesse caso $\beta_{2}=2$, pois podemos utilizar o item 1 de tamanho 10 para substituir por dois itens de tamanho $4\left(\beta_{2}=\left\lfloor\frac{10}{4}\right\rfloor=2\right)$.

Estes cortes duais restringem o conjunto de soluções duais, porém, o corte dual estendido é mais profundo. A Figura (3.6) ilustra os cortes duais. 


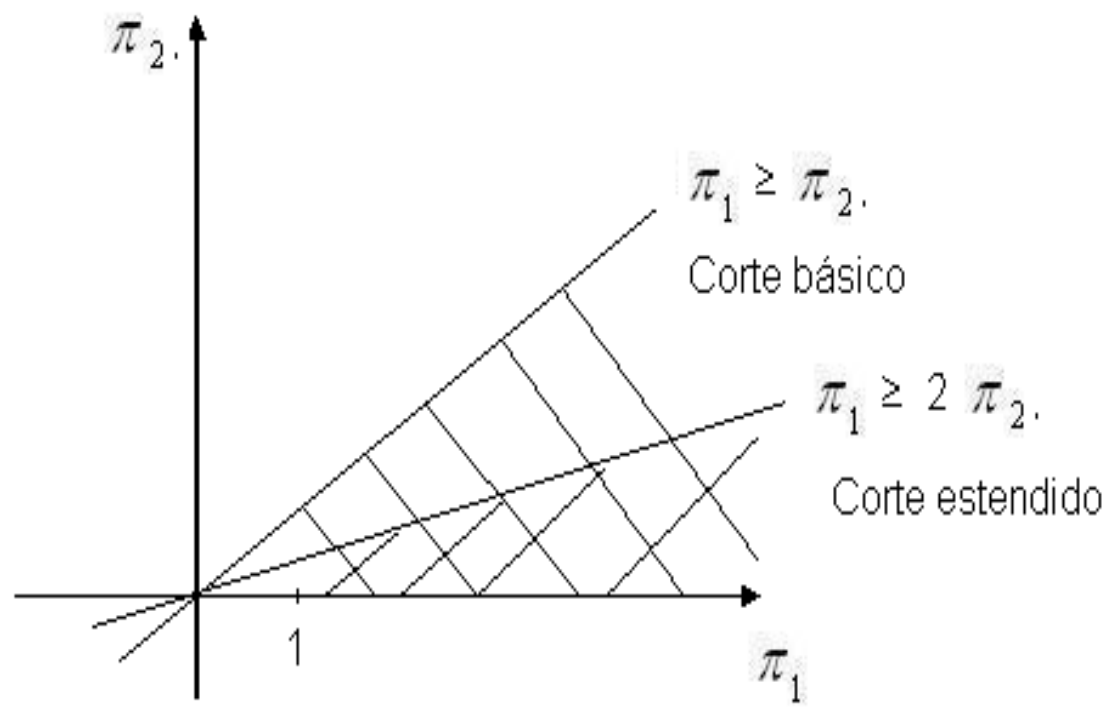

Figura 3.6: Corte dual básico e estendido.

O corte dual estendido consiste numa restrição válida para o problema dual conforme o teorema abaixo.

Proposição 3.2.1 Considere a nova família de cortes duais estendidos $-\pi_{i}+\sum_{s \in S} \beta_{s} \pi_{s} \leq$ 0 em que $S$ é tal que: $\sum_{s \in S} \beta_{s} \ell_{s} \leq \ell_{i}, \beta_{s}>0$ inteiro. Estas inequações são válidas para o espaço de soluções ótimas do dual do problema de corte unidimensional.

\section{Prova:}

O modelo de Gilmore e Gomory é $\min \left\{c^{T} x: A x=b, x \geq 0 \quad c=(1, \ldots, 1)\right\}$, sendo o seu dual $\max \left\{b^{T} \pi: A^{T} \pi \leq c\right\}$. Seja $\bar{\pi}$ a solução ótima dual. Esta solução dual é factível para o espaço do problema $D$ (espaço de soluções do problema dual), ou seja, $\bar{\pi} a_{j} \leq 1 \forall j \in A$. Suponha, para redução a um absurdo, que ela não obedece a um dos cortes duais, ou seja, $-\bar{\pi}_{i}+\sum_{s \in S} \beta_{s} \bar{\pi}_{s}>0$, com $\beta_{s}$ inteiro não negativo.

Para satisfazer a demanda de itens de largura $\ell_{i}$ na solução ótima, deve haver pelo menos uma variável básica positiva correspondente à um padrão de corte $a_{j}=$ $\left(a_{1 j}, \ldots, a_{i j}, \ldots, a_{s_{1 j}}, \ldots, a_{s_{|S|} j}, \ldots, a_{m j}\right)^{T}$ tal que $a_{i j}>0$. O seu custo reduzido é nulo, ou de uma forma equivalente, $\bar{\pi} a_{j}=1$.

Como $a_{i j}>0$ e $\beta_{s 1}, \ldots, \beta_{s_{|S|}}, a_{s_{|S|} j} \geq 0$, considere o padrão de corte $a_{j}^{\prime}=\left(a_{1 j}, \ldots, 0, \ldots, a_{s_{1 j}}+\beta_{s 1} a_{i j}, \ldots, a_{s_{|S|} j}+\beta_{s_{|S|}} a_{i j}, \ldots, a_{m j}\right)^{T}$, gerado a partir de $a_{j}$ substituindo-se os seus itens de largura $\ell_{i}$ pela combinação $\sum_{s \in S} \beta_{s} \ell_{s}$. Temos que: 


$$
\begin{aligned}
& \bar{\pi} a_{j}^{\prime}= \\
& \left(\bar{\pi}_{1}, \bar{\pi}_{2}, \ldots, \bar{\pi}_{i}, \ldots, \bar{\pi}_{s_{1}}, \ldots, \bar{\pi}_{S_{|S|}}, \ldots, \bar{\pi}_{m}\right)\left(a_{1 j}, \ldots, 0, \ldots, a_{s_{1} j}+\beta_{s 1} a_{i j}, \ldots, \beta_{s_{|S|}} a_{s_{|S|} j}+\right. \\
a_{i j}, \ldots, & \left.a_{m j}\right)^{T}= \\
& \bar{\pi}_{1} a_{1 j}+\cdots+\bar{\pi}_{s_{1}}\left(a_{s_{1} j}+\beta_{s 1} a_{i j}\right)+\cdots+\bar{\pi}_{S_{|S|}}\left(a_{s_{|S|} j}+\beta_{s_{|S|} \mid} a_{i j}\right)+\cdots+\bar{\pi}_{m} a_{m j}= \\
& \bar{\pi}_{1} a_{1 j}+\cdots+\bar{\pi}_{s_{1}} a_{s_{1} j}+\cdots+\bar{\pi}_{S_{|S|}} a_{s_{|S|} j}+\cdots+\bar{\pi}_{m} a_{m j}+a_{i j}\left(\beta_{s 1} \bar{\pi}_{s_{1}}+\cdots+\beta_{s_{|S|}} \bar{\pi}_{S_{|S|}}\right)
\end{aligned}
$$

Uma vez que $\sum_{s \in S} \beta_{s} \bar{\pi}_{s}>\bar{\pi}_{i}$ (suposto, por absurdo) temos:

$$
\bar{\pi}_{1} a_{1 j}+\cdots+\bar{\pi}_{s_{1}} a_{s_{1} j}+\cdots+\bar{\pi}_{S_{|S|}} a_{s_{|S|} j}+\cdots+\bar{\pi}_{m} a_{m j}+a_{i j}\left(\beta_{s 1} \bar{\pi}_{s_{1}}+\cdots+\beta_{s_{|S|}} \bar{\pi}_{S_{|S|}}\right)>
$$$$
\bar{\pi}_{1} a_{1 j}+\cdots+\bar{\pi}_{s_{1}} a_{s_{1 j}}+\cdots+\bar{\pi}_{S_{|S|}} a_{s_{|S|} j}+\cdots+\bar{\pi}_{m} a_{m j}+a_{i j} \bar{\pi}_{i}=\bar{\pi}_{1} a_{1 j}+\cdots+\bar{\pi}_{i} a_{i j}+\cdots+
$$$$
\bar{\pi}_{s_{1}} a_{s_{1} j}+\cdots+\bar{\pi}_{S_{|S|}} a_{s_{|S|} j}+\cdots+\bar{\pi}_{m} a_{m j}=1
$$

Portanto, se $\bar{\pi}_{i}<\sum_{s \in I} \beta_{s} \bar{\pi}_{s}$ (isto é, $\bar{\pi}$ não satisfaz o corte dual), e como $\bar{\pi} a_{j}=1$, então $\bar{\pi} a_{j}^{\prime}>1$. Assim o vetor $a_{j}^{\prime}$ que é associado a um padrão de corte e define uma restrição para o espaço dual, $\pi a_{j}^{\prime} \leq 1$, que é violada pela solução dual $\bar{\pi}$. Absurdo, pois $\pi a_{j} \leq 1$ para todo vetor $a_{j}$ associado a um padrão de corte. Portanto, $\bar{\pi} a_{j}^{\prime} \leq 1$.

\subsubsection{Uma Família de cortes duais para os objetos}

Para a aplicação dos corte duais associados aos objetos Valério de Carvalho utiliza os problemas primais e duais respectivamente abaixo:

$$
\begin{aligned}
& \text { Min } f(x)=c^{T} x+f^{T} y \quad \text { Max } g(\pi, v)=b^{T} \pi+e^{T} v \\
& \text { s.a. }\left\{\begin{array} { l } 
{ A x = b } \\
{ E x \leq e } \\
{ x \geq 0 }
\end{array} \Leftrightarrow \quad \text { s.a. } \left\{\begin{array}{c}
A^{T} \pi+E^{T} v \leq c \\
\pi \text { irrestrito, } v \leq 0
\end{array}\right.\right.
\end{aligned}
$$

em que os custos dos objetos são os seus próprios comprimentos $c_{k}=L_{k}, k=1, \cdots, K$.

Analogamente aos itens, suponhamos que um objeto $k$ satisfaça:

$$
L_{k^{\prime}} \leq L_{k}
$$

isto é, o objeto de índice $k$ é maior do que o objeto de índice $k^{\prime}$, então a seguinte restrição pode ser incluída no problema dual sem perda de solução ótima:

$$
v_{k}-v_{k^{\prime}} \leq L_{k}-L_{k^{\prime}}, \quad k=1, \ldots, K-1, \quad k^{\prime}=2, \ldots, K
$$


Isto produz uma coluna no problema primal da forma:

$$
\left(\begin{array}{c}
0 \\
\vdots \\
0 \\
\cdots \\
1 \\
\vdots \\
-1
\end{array}\right)
$$

Estas restrições são inseridas no problema dual criando o problema "dual estendido". O respectivo problema primal, chamado "primal estendido", pode ser resolvido por geração de colunas. A base ótima será da forma:

$$
\left[\begin{array}{cccccc}
a_{111} & \ldots & a_{1 p k} & 0 & \ldots & 0 \\
a_{211} & \ldots & a_{2 p k} & 0 & \ldots & 0 \\
\vdots & \ldots & \vdots & 0 & \ldots & 0 \\
a_{m 11} & \ldots & a_{m p k} & 0 & \ldots & 0 \\
\ldots & \ldots & \ldots & \ldots & \ldots & \ldots \\
1 & \ldots & 0 & 1 & \ldots & 0 \\
0 & \ldots & 0 & -1 & \ldots & 1 \\
0 & \ldots & 1 & 0 & \ldots & -1
\end{array}\right]
$$

isto é, as $p$ primeiras colunas são padrões de corte e as $(n-p)$ últimas colunas são devido aos cortes introduzidos.

\subsubsection{Uma nova interpretação dos cortes duais para os objetos}

Seja o objeto de índice $k$ e o objeto de índice $k^{\prime}\left(L_{k} \geq L_{k^{\prime}}\right)$ e o corte dual:

$$
v_{k}-v_{k^{\prime}} \leq L_{k}-L_{k^{\prime}}
$$

Seja o padrão de corte dado por

$a_{11}=\left(a_{111}, \ldots, a_{211}, \ldots, a_{m 11}, 0, \ldots, 0,1\right)$ (o número 1 esta na posição $m+k^{\prime}$ do padrão) e suponha que $L_{k} \geq L_{k^{\prime}}$ (i. é., o padrão esta sendo cortado em um objeto de índice $k^{\prime}$ 
porém temos um objeto maior, de índice $k$, em que podemos corta-lo ). Podemos construir um novo padrão de corte cortado em uma barra maior de índice $k$ o qual tem a seguinte coluna associada: $a_{12}=\left(a_{111}, \ldots, a_{211}, \ldots, a_{m 11}, 1,0, \ldots, 0\right)$.

Observe que:

$$
a_{12}-a_{11}=\left(\begin{array}{c}
a_{111} \\
\vdots \\
a_{m 11} \\
\vdots \\
1 \\
0 \\
\vdots \\
0
\end{array}\right)-\left(\begin{array}{c}
a_{111} \\
\vdots \\
a_{m 11} \\
\vdots \\
0 \\
1 \\
\vdots \\
0
\end{array}\right)=\left(\begin{array}{c}
0 \\
\vdots \\
0 \\
\vdots \\
1 \\
-1 \\
\vdots \\
0
\end{array}\right)=f_{1}
$$

Os elementos $(+1)$ e $(-1)$ estão nas posições $(m+k)$ e $\left(m+k^{\prime}\right)$ respectivamente. Assim, $f_{1}=(0, \ldots, 0,1,-1, \ldots, 0)^{T}$ é exatamente a coluna associada ao corte dual de Valério de Carvalho, sendo que seu custo é $F_{1}=L_{k}-L_{k^{\prime}}$. Podemos interpretar os cortes duais como operações elementares (subtração entre colunas) nas colunas da matriz A, o que corresponde a uma mudança de variável (uma nova variável surge para a nova coluna). Observe que estas novas colunas (decorrentes dos corte duais) podem ser geradas a priore, sem a necessidade de se conhecer os padrões, como Valério de Carvalho percebeu. Esta nova interpretação nos permite definir novas famílias de cortes (veja seção 3.2.8 )

\subsubsection{Recuperando a solução do problema primal}

Tendo a solução ótima do problema primal estendido, a qual pode conter colunas associadas aos cortes duais:

$$
a_{11} x_{1}+\cdots+a_{p k} x_{p}+f_{1} y_{1}+\cdots+f_{r} y_{r}=e
$$

desejamos encontrar uma solução do problema primal, na qual as variáveis associadas aos cortes duais são nulas: 


$$
a_{11} x_{1}^{\prime}+a_{21} x_{2}^{\prime}+\ldots+a_{p k} x_{p}^{\prime}+a_{p+1} x_{p+1}^{\prime}+\cdots=e
$$

Possivelmente outros padrões de corte serão necessários para $a_{p+1}, \ldots$ Para iniciar o processo tomamos o primeiro corte dual que possui o $(-1)$ na linha de maior índice, e em seguida escolhemos aleatoriamente um padrão de corte que possui objetos na mesma linha referente a linha do corte dual que possui o $(-1)$. Sem perda de generalidade, suponha que seja o primeiro padrão de corte e o primeiro corte dual, com isso temos a seguinte igualdade.

$$
a_{11} x_{1}+f_{1} y_{1}+\cdots=e
$$

isolando o padrão de corte e o corte dual encontramos:

$$
a_{11} x_{1}+f_{1} y_{1}=e^{\prime}
$$

Primeiramente substituímos na solução 3.23 o corte dual $f_{1}=a_{12}-a_{11}$ encontrando o seguinte:

$$
a_{11}\left(x_{1}-y_{1}\right)+a_{21} y_{1}=e^{\prime}
$$

Para que a nova solução seja factível devemos ter:

$$
\left(x_{1}-y_{1}\right) \geq 0
$$

Caso isso aconteça, seguindo as atribuições abaixo, encontramos uma solução do problema primal na qual o corte dual é eliminado. Desta forma selecionamos outro corte dual e outro padrão de corte e repetimos a substituição de variáveis com o intuito de eliminarmos todas as varáveis associadas aos cortes duais.

$$
x_{1}^{\prime}=x_{1}-y_{1} \quad x_{2}^{\prime}=y_{1}
$$

Portanto temos a solução do problema primal

$$
a_{11} x_{1}^{\prime}+a_{12} x_{2}^{\prime}+\cdots=e
$$


Caso a desigualdade 3.26 não seja obedecida $e^{\prime}$ é escrito como combinação linear positiva de $f_{1}$ e $a_{12}$.

Em relação aos objetos isto significa que o corte dual $f_{1}$ deve transferir o corte de um padrão em uma freqüência maior que o padrão de corte $a_{11}$ disponibiliza, assim o padrão de corte $a_{11}$ não será mais utilizado e o valor da variável relativa ao corte dual $F_{1}$ decresce gerando a solução abaixo.

$$
f_{1}\left(y_{1}-x_{1}\right)+a_{2} x_{1}=b^{\prime}
$$

Como o corte dual permanece na solução selecionamos outro padrão de corte e repetimos a substituição de variáveis com o intuito de eliminarmos todas as varáveis associadas aos cortes duais.

\subsubsection{Proposta para uma nova família de cortes duais}

A família de novos cortes proposta se baseia em extensões dos cortes básicos propostos por Valério de Carvalho.

Corte básico dos objetos: $L_{k}^{\prime} \leq L_{k} \Rightarrow \pi_{k}-\pi_{k^{\prime}} \leq L_{k}-L_{k^{\prime}}$.

Corte estendido dos objetos: $\beta L_{k}^{\prime} \leq L_{k} \Rightarrow \pi_{k}-\pi_{k^{\prime}} \leq L_{k}-L_{k^{\prime}} \quad \beta>0$ e inteiro.

Utilizamos $\beta=\left\lfloor\frac{L_{k}}{L_{k}^{\prime}}\right\rfloor$ para representar a quantidade inteira positiva que um objeto menor pode ser utilizado por um objeto maior.

Veremos em um exemplo como ambos os cortes se comportam:

Consideremos dois objetos $L_{1}=21$ e $L_{2}=10$.

As desigualdades de Valério de Carvalho são : $-\pi_{1}+\pi_{2} \leq L_{1}-L_{2}(10 \leq 21)$.

As desigualdades relativas aos cortes estendidos são : $-\pi_{1}+\beta \pi_{2} \leq L_{1}-\beta L_{2}$ $(2 * 10 \leq 21)$.

Nesse caso $\beta=2$, pois podemos utilizar o padrão que esta sendo contado no objeto 2 de tamanho 10 e repeti-lo duas vezes no objeto 1 de tamanho $21\left(\beta=\left\lfloor\frac{21}{10}\right\rfloor=2\right)$. 


\subsubsection{Exemplo}

Considere um problema com três itens ( em relação aos cortes duais nos objetos a quantidade de itens, seus comprimentos e suas demandas não são relevantes em relação a recuperação da solução.) e dois objetos : $L_{1}=20 \mathrm{~cm}, L_{2}=10 \mathrm{~cm}$, com os respectivas custos $c_{1}=20$ e $c_{2}=10$ e suas disponibilidades em estoque $e_{1}=12$ e $e_{2}=4$.

Considere o sistema abaixo como resultado obtido por geração de colunas do problema de corte de estoque sugerido acima, pois como visto os cortes duais são válidos para toda solução dual:

$$
5\left(\begin{array}{c}
1 \\
2 \\
\ldots \\
0 \\
1
\end{array}\right)+8\left(\begin{array}{c}
2 \\
2 \\
\ldots \\
0 \\
1
\end{array}\right)+9\left(\begin{array}{c}
0 \\
0 \\
\ldots \\
1 \\
-1
\end{array}\right)=\left(\begin{array}{c}
21 \\
16 \\
\ldots \\
9 \\
4
\end{array}\right)
$$

O corte dual indica que temos 9 objetos do tipo 2 em excesso, logo temos:

$y_{1}>x_{1}(9>5)$, logo o padrão é esgotado porém o $y$ correspondente não é zerado, ou seja, substituímos o objeto 2 pelo objeto 1 para cortar o padrão de corte, atualizando as variáveis:

$$
x_{1}^{\prime}=x_{1}=5 ; \quad y_{1}=y_{1}-x_{1}=9-5=4 ; \quad x_{1}=0
$$

Atualizando a solução:

$$
5\left(\begin{array}{c}
1 \\
2 \\
\ldots \\
1 \\
0
\end{array}\right)+8\left(\begin{array}{c}
2 \\
2 \\
\ldots \\
0 \\
1
\end{array}\right)+4\left(\begin{array}{c}
0 \\
0 \\
\ldots \\
1 \\
-1
\end{array}\right)=\left(\begin{array}{c}
21 \\
16 \\
\ldots \\
9 \\
4
\end{array}\right)
$$

Podemos contabilizar a quantidade dos objetos:

- Objeto $1: 5 * 1+8 * 0+4 * 1=9$

- Objeto 2: $5 * 0+8 * 1+4 *(-1)=4$

Podemos também contabilizar o custo, considerando que a função objetivo seja 
minimizar o comprimento cortado(minimizar $\left.f(x)=\sum_{k=1}^{k} \sum_{j=1}^{P} L_{k} x_{j k}\right)$ :

$$
\text { - } f(x)=L_{1} x_{1}^{\prime}+L_{2} x_{2}+F_{1} f_{1}=5 * 20+8 * 10+4 * 10=220
$$

Custo obtido antes da aplicação do procedimento para recuperar a solução do problema original $f(x)=220$

Tomemos o próximo padrão de corte válido: $a_{22}$

$y_{1}<a_{22}(4<8)$, logo temos mais objetos do que o corte dual esta requisitando, atualizando as variáveis:

$$
x_{2}^{\prime}=x_{2}-y_{1}=8-4=4 ; \quad x_{2}=y_{1} \quad y_{1}=0
$$

Logo com o fim do procedimento a variável associada ao corte dual é anulada, atualizando os padrões:

$$
5\left(\begin{array}{c}
1 \\
2 \\
\cdots \\
1 \\
0
\end{array}\right)+4\left(\begin{array}{c}
2 \\
2 \\
\ldots \\
0 \\
1
\end{array}\right)+4\left(\begin{array}{c}
2 \\
2 \\
\ldots \\
0 \\
1
\end{array}\right)=\left(\begin{array}{c}
21 \\
16 \\
\ldots \\
9 \\
4
\end{array}\right)
$$

Podemos contabilizar as demandas dos itens:

- Objeto 1: $5 * 1+4 * 0+4 * 1=9$

- Objeto $2: 5 * 0+4 * 0+4 * 1=4$

Podemos também contabilizar o custo, lembrando que a função objetivo tenta minimizar o número de objetos cortados (minimizar $f(x)=\sum_{j=1}^{J} x_{j}$ ):

- $f(x)=L_{1} x_{1}^{\prime}+L_{2} x_{2}+L_{1} x_{2}^{\prime}=20 * 5+4 * 10+4 * 20=220$

Custo obtido antes da aplicação do procedimento para recuperar a solução do problema original $f(x)=220$, notemos que o custo (minimizar o comprimento cortado) permanece inalterado.

Podemos alterar a solução que contém corte duais $\left(y_{s}>0\right)$, transformando-os em padrões de corte válidos, utilizando uma mudança de variáveis como já foi mostrado. 


\section{Capítulo 4}

\section{Experimentos Computacionais}

Realizamos alguns testes computacionais para comparar os resultados do método de geração de colunas sem cortes duais e a geração de colunas com cortes duais dos itens. Os cortes duais dos objetos não tiveram resultados computacionais conclusivos até a edição deste texto. Os cortes duais introduzidos foram:

Corte GG: cortes duais do tipo Gilmore e Gomory que gera a seguinte coluna no problema primal; $(0, \ldots, 0,-1,0, \ldots, 0)^{T}$;

Corte 1: Corte básico com $|S|=1$;

Corte 2: Corte básico com $|S|=2$;

Corte E: Corte estendido $|S|=1$ e $\beta_{s}=\left\lfloor\frac{\ell_{i}}{\ell_{j}}\right\rfloor$;

Corte GG e 1 e 2 : os cortes GG, 1 e 2 são considerados em conjunto;

Corte GG e 1 e 2 e estendido: os cortes GG, 1, 2 e estendido são considerados em conjunto.

Os algoritmos foram implementados em Delphi 5 e os testes foram executados em um microcomputador Athlon XP 2.2 MHZ com 512 Mb de RAM. O Método Simplex com geração de colunas foi adaptado de Poldi [12] bem como os parâmetros dos intervalos citados abaixo. Os exemplos estão divididos em 4 classes com 10 problemas-teste que estão detalhados na tabela (4.1). As características do gerador seguem abaixo:

- comprimentos dos itens $l_{i} \in[0.01 L, 0.8 L]$;

- demandas dos itens: $d_{i} \in[70,120]$.

As classes estão especificadas na tabela abaixo. 
Tabela 4.1: Classes dos testes (média de 10 exemplos em cada classe)

\begin{tabular}{|c|c|c|}
\hline Classe & Tamanho da barra & número de itens \\
\hline 1 & 250 & 45 \\
\hline 2 & 250 & 70 \\
\hline 3 & 500 & 45 \\
\hline 4 & 500 & 70 \\
\hline
\end{tabular}

Os cortes duais nos itens foram introduzidos no Método Simplex com geração de colunas em momentos diferentes. Utilizamos os múltiplos do número de itens para introduzir os cortes duais na geração de colunas, ou seja, até o número especificado fazemos apenas mochilas, quando o número de iterações ultrapassa o múltiplo determinado começamos a fazer mochilas ou cortes duais dependendo de qual é mais atrativo a entrar na base (menor custo relativo).

A primeira coluna das tabela (4.2) e (4.3) mostra as iterações que foram consideradas para introduzir os cortes duais na geração de colunas, sendo que $m$ é o número de itens. Assim para $m=0$ os cortes duais são considerados desde o início, $m=1$ os cortes duais são considerados após m iterações de mochila (por exemplo, nos problemas da classe 1 da tabela 4.1 os cortes são introduzidos após 45 iterações), $m=3$ introduzimos os cortes após $3 * m$ iterações (na mesma classe citada anteriormente os cortes duais seriam introduzidos após 135 iterações) e, por fim, $m=5$ introduz os cortes após 225 iterações. Esta investigação decorre do fato que nas primeiras iterações o Método Simplex tem se comportado fazendo com que a função objetivo decresça significativamente sendo que esse decréscimo diminua quando nos aproximamos da otimalidade. Isto poderia sugerir que seria melhor não introduzir os cortes duais de início.

A segunda coluna descreve os cortes duais utilizados, por exemplo na linha 5 da tabela (4.2) utilizamos os cortes de Gilmore e Gomory e os cortes Estendido, na linha 14 da mesma tabela utilizamos todos os cortes duais; Gilmore e Gomory, corte básico 1, 2 e o corte estendido. A terceira coluna armazena o número de mochilas que foram resolvidas e a quarta coluna representa o número de iterações Simplex que foram feitas, ou seja, a soma do número de mochilas mais o número de cortes duais (consideramos uma iteração Simplex uma atualização da matrix básica tanto por uma mochila como por um corte dual). 
A quinta coluna refere-se ao tempo computacional total, considerando a resolução e a recuperação da solução. Por fim, a sexta coluna refere-se a cauda citada no primeiro capítulo que informa se o valor do módulo da diferença entre as $i$-ésima e ( $i$-1) - ésima iterações da função objetivo for menor que $10 \%$ do que o valor do módulo da diferença entre as (i-1)-ésima e (i-2) - ésima iterações da função objetivo. Essa consideração foi feita como referência para introduzirmos os cortes duais, porém, resultados nos levaram a introduzir os cortes duais utilizando múltiplos dos valores dos itens.

As tabelas (4.2) e (4.3) se referem a classe 1 da tabela 4.1

Tabela4.2: Valores Absolutos

Tabela 4.3: Porcentagem de redução

\begin{tabular}{|c|c|c|c|c|c|c|c|c|c|c|c|c|}
\hline & Múltiplos de m & Cortes & Mochilas & Iterações & Tempo & Cauda & Múltiplos de $\mathrm{m}$ & Cortes & Mochilas & Iterações & Tempo & Cauda \\
\hline 1 & $\mathrm{~m}=45$ & Sem Cortes & 393,60 & 393,60 & 26,30 & 113,90 & $\mathrm{~m}=45$ & Sem Cortes & $0 \%$ & $0 \%$ & $0 \%$ & $0 \%$ \\
\hline 2 & 0 & GG & 202,70 & 282,50 & 1,05 & 1,00 & 0 & GG & $48,50 \%$ & $28,23 \%$ & $96,01 \%$ & $99,12 \%$ \\
\hline 3 & 0 & $\mathrm{GG}, 1$ & 126,70 & 328,70 & 1,03 & 1,60 & 0 & GG, 1 & $67,81 \%$ & $16,49 \%$ & $96,10 \%$ & $98,60 \%$ \\
\hline 4 & 0 & GG, 2 & 55,80 & 644,90 & 0,88 & 3,80 & 0 & GG, 2 & $85,82 \%$ & $-63,85 \%$ & $96,65 \%$ & $96,66 \%$ \\
\hline 5 & 0 & GG, E & 74,20 & 486,50 & 0,95 & 3,90 & 0 & GG, E & $81,15 \%$ & $-23,60 \%$ & $96,40 \%$ & $96,58 \%$ \\
\hline 6 & 0 & GG, 1,2 & 53,20 & 572,00 & 0,89 & 2,40 & 0 & GG, 1,2 & $86,46 \%$ & $-45,33 \%$ & $96,62 \%$ & $97,89 \%$ \\
\hline 7 & 0 & $\mathrm{GG}, 1,2, \mathrm{E}$ & 50,20 & 681,30 & 0,91 & 2,60 & 0 & $\mathrm{GG}, 1,2, \mathrm{E}$ & $87,25 \%$ & $-73,09 \%$ & $96,54 \%$ & $97,72 \%$ \\
\hline 8 & 0 & $\mathrm{E}$ & 79,10 & 546,40 & 0,95 & 3,20 & 0 & $\mathrm{E}$ & $79,90 \%$ & $-38,82 \%$ & $96,40 \%$ & $97,19 \%$ \\
\hline 9 & 1 & GG & 224,20 & 291,40 & 1,07 & 1,00 & 1 & GG & $43,04 \%$ & $25,97 \%$ & $95,92 \%$ & $99,12 \%$ \\
\hline 10 & 1 & GG, 1 & 150,10 & 319,20 & 1,04 & 1,50 & 1 & GG, 1 & $61,86 \%$ & $18,90 \%$ & $96,05 \%$ & $98,68 \%$ \\
\hline 11 & 1 & GG, 2 & 98,50 & 664,50 & 0,94 & 4,70 & 1 & GG, 2 & $74,97 \%$ & $-68,83 \%$ & $96,42 \%$ & $95,87 \%$ \\
\hline 12 & 1 & GG, E & 109,90 & 503,50 & 0,99 & 1,90 & 1 & GG, E & $72,08 \%$ & $-27,92 \%$ & $96,22 \%$ & $98,33 \%$ \\
\hline 13 & 1 & $\mathrm{GG}, 1,2$ & 93,30 & 581,70 & 0,93 & 1,50 & 1 & $\mathrm{GG}, 1,2$ & $76,30 \%$ & $-47,79 \%$ & $96,45 \%$ & $98,68 \%$ \\
\hline 14 & 1 & $\mathrm{GG}, 1,2, \mathrm{E}$ & 85,90 & 698,40 & 0,90 & 2,20 & 1 & $\mathrm{GG}, 1,2, \mathrm{E}$ & $78,18 \%$ & $-77,44 \%$ & $96,58 \%$ & $98,07 \%$ \\
\hline 15 & 1 & $\mathrm{E}$ & 113,10 & 520,00 & 1,00 & 2,50 & 1 & $\mathrm{E}$ & $71,27 \%$ & $-32,11 \%$ & $96,20 \%$ & $97,81 \%$ \\
\hline 16 & 3 & GG & 261,70 & 297,80 & 1,11 & 0,50 & 3 & GG & $33,51 \%$ & $24,34 \%$ & $95,77 \%$ & $99,56 \%$ \\
\hline 17 & 3 & GG, 1 & 209,20 & 323,70 & 1,04 & 0,90 & 3 & GG, 1 & $46,85 \%$ & $17,76 \%$ & $96,05 \%$ & $99,21 \%$ \\
\hline 18 & 3 & GG, 2 & 170,90 & 541,70 & 0,97 & 1,40 & 3 & GG, 2 & $56,58 \%$ & $-37,63 \%$ & $96,32 \%$ & $98,77 \%$ \\
\hline 19 & 3 & GG, E & 182,40 & 432,80 & 0,99 & 1,10 & 3 & GG, E & $53,66 \%$ & $-9,96 \%$ & $96,24 \%$ & $99,03 \%$ \\
\hline 20 & 3 & $\mathrm{GG}, 1,2$ & 168,50 & 494,50 & 0,90 & 1,60 & 3 & $\mathrm{GG}, 1,2$ & $57,19 \%$ & $-25,64 \%$ & $96,60 \%$ & $98,60 \%$ \\
\hline 21 & 3 & $\mathrm{GG}, 1,2, \mathrm{E}$ & 167,00 & 549,20 & 0,99 & 3,00 & 3 & $\mathrm{GG}, 1,2, \mathrm{E}$ & $57,57 \%$ & $-39,53 \%$ & $96,25 \%$ & $97,37 \%$ \\
\hline 22 & 3 & $\mathrm{E}$ & 188,40 & 488,40 & 1,10 & 1,70 & 3 & $\mathrm{E}$ & $52,13 \%$ & $-24,09 \%$ & $95,84 \%$ & $98,51 \%$ \\
\hline 23 & 5 & GG & 275,90 & 287,50 & 1,06 & 0,30 & 5 & GG & $29,90 \%$ & $26,96 \%$ & $95,97 \%$ & $99,74 \%$ \\
\hline 24 & 5 & GG, 1 & 252,50 & 288,80 & 0,96 & 0,00 & 5 & GG, 1 & $35,85 \%$ & $26,63 \%$ & $96,36 \%$ & $100 \%$ \\
\hline 25 & 5 & GG, 2 & 239,30 & 346,10 & 0,94 & 0,60 & 5 & GG, 2 & $39,20 \%$ & $12,07 \%$ & $96,43 \%$ & $99,47 \%$ \\
\hline 26 & 5 & GG, E & 246,20 & 331,20 & 1,01 & 0,90 & 5 & GG, E & $37,45 \%$ & $15,85 \%$ & $96,17 \%$ & $99,21 \%$ \\
\hline 27 & 5 & $\mathrm{GG}, 1,2$ & 238,70 & 334,30 & 0,93 & 0,60 & 5 & $\mathrm{GG}, 1,2$ & $39,35 \%$ & $15,07 \%$ & $96,48 \%$ & $99,47 \%$ \\
\hline 28 & 5 & $\mathrm{GG}, 1,2, \mathrm{E}$ & 238,40 & 368,70 & 0,95 & 0,70 & 5 & $\mathrm{GG}, 1,2, \mathrm{E}$ & $39,43 \%$ & $6,33 \%$ & $96,37 \%$ & $99,39 \%$ \\
\hline 29 & 5 & $\mathrm{E}$ & 245,40 & 322,50 & 1,00 & 0,60 & 5 & $\mathrm{E}$ & $37,65 \%$ & $18,06 \%$ & $96,19 \%$ & $99,47 \%$ \\
\hline
\end{tabular}

Tomemos por exemplo a linha 10, em que foram aplicados os cortes básico 1 e cortes de Gilmore e Gomory; esses cortes produziram em média 150,10 mochilas enquanto a geração de colunas padrão produziu 393,60 mochilas, o que representa 61,86\% de redução no numero de mochilas (tabela 4.3). Em relação as iterações Simplex tivemos 319,20 iterações (ou seja 150,10 mochilas e 169,1 cortes duais), o que representa 18,90\% de redução, feitas em 1,04 segundos representando uma redução de 96,05\% em relação ao tempo. Podemos ver que a redução do número de mochilas dependem do momento em 
que os cortes duais são inseridos, sendo que quando mais cedo são inseridos a redução de mochilas é maior. O caso em que todos os cortes são considerados tivemos redução de $87 \%$ (linha 7)quando os cortes atuam desde o início e 39\% (linha 28) quando foram inseridos após $225\left(5^{*} m\right)$ iterações. Apesar disso, o número de iterações Simplex aumentou, considerando o mesmo caso tivemos $73 \%$ de aumento nas iterações Simplex e quando introduzimos após $225\left(5^{*} \mathrm{~m}\right)$ iterações tivemos $6 \%$ de redução de iterações Simplex. Em relação a cauda e tempo, as reduções foram acima de $90 \%$.

As tabelas (4.4) e (4.5) se referem a classe 2 da tabela 4.1

Tabela4.4: Valores Absolutos

Tabela 4.5: Porcentagem de redução

\begin{tabular}{|c|c|c|c|c|c|c|c|c|c|c|c|c|}
\hline & Múltiplos de $\mathrm{m}$ & Cortes & Mochilas & Iterações & Tempo & Cauda & Múltiplos de $\mathrm{m}$ & Cortes & Mochilas & Iterações & Tempo & Cauda \\
\hline 1 & $\mathrm{~m}=70$ & Sem Cortes & 1068,50 & 1068,50 & 49,58 & 203,40 & $\mathrm{~m}=45$ & Sem Cortes & $0 \%$ & $0 \%$ & $0 \%$ & $0 \%$ \\
\hline 2 & 0 & GG & 581,10 & 798,10 & 3,30 & 2,40 & 0 & GG & $45,62 \%$ & $25,31 \%$ & $93,33 \%$ & $98,22 \%$ \\
\hline 3 & 0 & GG, 1 & 352,50 & 1065,90 & 3,31 & 2,90 & 0 & GG, 1 & $67,01 \%$ & $0,24 \%$ & $93,32 \%$ & $98,57 \%$ \\
\hline 4 & 0 & GG, 2 & 91,80 & 2127,40 & 3,07 & 8,20 & 0 & GG, 2 & $91,41 \%$ & $-99,10 \%$ & $93,82 \%$ & $95,97 \%$ \\
\hline 5 & 0 & GG, E & 161,70 & 1477,90 & 2,64 & 8,30 & 0 & GG, E & $84,87 \%$ & $-38,32 \%$ & $94,68 \%$ & $95,92 \%$ \\
\hline 6 & 0 & GG, 1,2 & 92,20 & 1879,20 & 3,12 & 5,50 & 0 & GG, 1,2 & $91,37 \%$ & $-75,87 \%$ & $93,71 \%$ & $97,30 \%$ \\
\hline 7 & 0 & $\mathrm{GG}, 1,2, \mathrm{E}$ & 86,30 & 2287,90 & 3,43 & 6,90 & 0 & $\mathrm{GG}, 1,2, \mathrm{E}$ & $91,92 \%$ & $-114,12 \%$ & $93,09 \%$ & $96,61 \%$ \\
\hline 8 & 0 & $\mathrm{E}$ & 171,80 & 1607,50 & 2,81 & 7,20 & 0 & $\mathrm{E}$ & $83,92 \%$ & $-50,44 \%$ & $94,34 \%$ & $96,46 \%$ \\
\hline 9 & 1 & GG & 634,60 & 845,60 & 3,78 & 2,20 & 1 & GG & $40,61 \%$ & $20,86 \%$ & $92,38 \%$ & $98,92 \%$ \\
\hline 10 & 1 & GG, 1 & 403,90 & 1103,40 & 3,25 & 1,50 & 1 & GG, 1 & $62,20 \%$ & $-3,27 \%$ & $93,44 \%$ & $99,26 \%$ \\
\hline 11 & 1 & GG, 2 & 155,80 & 2053,50 & 3,06 & 7,00 & 1 & GG, 2 & $85,42 \%$ & $-92,19 \%$ & $93,83 \%$ & $96,56 \%$ \\
\hline 12 & 1 & GG, E & 227,20 & 1627,60 & 2,95 & 7,60 & 1 & GG, E & $78,74 \%$ & $-52,33 \%$ & $94,04 \%$ & $96,26 \%$ \\
\hline 13 & 1 & $\mathrm{GG}, 1,2$ & 153,90 & 1857,70 & 2,98 & 4,20 & 1 & GG, 1,2 & $85,60 \%$ & $-73,86 \%$ & $93,98 \%$ & $97,94 \%$ \\
\hline 14 & 1 & $\mathrm{GG}, 1,2, \mathrm{E}$ & 148,80 & 2211,20 & 3,34 & 6,90 & 1 & $\mathrm{GG}, 1,2, \mathrm{E}$ & $86,07 \%$ & $-106,94 \%$ & $93,26 \%$ & $96,61 \%$ \\
\hline 15 & 1 & $\mathrm{E}$ & 217,90 & 1575,70 & 2,48 & 6,00 & 1 & $\mathrm{E}$ & $79,61 \%$ & $-47,47 \%$ & $95,00 \%$ & $97,05 \%$ \\
\hline 16 & 3 & GG & 683,30 & 815,30 & 3,15 & 1,40 & 3 & GG & $36,05 \%$ & $23,70 \%$ & $93,64 \%$ & $99,31 \%$ \\
\hline 17 & 3 & GG, 1 & 509,90 & 1175,20 & 3,50 & 4,00 & 3 & GG, 1 & $52,28 \%$ & $-9,99 \%$ & $92,95 \%$ & $98,03 \%$ \\
\hline 18 & 3 & $\mathrm{GG}, 2$ & 286,80 & 2095,20 & 3,16 & 5,10 & 3 & GG, 2 & $73,16 \%$ & $-96,09 \%$ & $93,63 \%$ & $97,49 \%$ \\
\hline 19 & 3 & GG, E & 347,20 & 1552,00 & 2,99 & 3,40 & 3 & GG, E & $67,51 \%$ & $-45,25 \%$ & $93,97 \%$ & $98,33 \%$ \\
\hline 20 & 3 & GG, 1,2 & 281,70 & 1857,90 & 2,98 & 3,30 & 3 & GG, 1,2 & $73,64 \%$ & $-73,88 \%$ & $93,98 \%$ & $98,38 \%$ \\
\hline 21 & 3 & $\mathrm{GG}, 1,2, \mathrm{E}$ & 279,70 & 2261,40 & 3,46 & 8,50 & 3 & $\mathrm{GG}, 1,2, \mathrm{E}$ & $73,82 \%$ & $-111,64 \%$ & $93,02 \%$ & $95,82 \%$ \\
\hline 22 & 3 & $\mathrm{E}$ & 351,20 & 1629,50 & 2,99 & 3,40 & 3 & $\mathrm{E}$ & $67,13 \%$ & $-52,50 \%$ & $93,97 \%$ & $98,33 \%$ \\
\hline 23 & 5 & GG & 776,50 & 861,50 & 3,45 & 1,50 & 5 & GG & $27,33 \%$ & $19,37 \%$ & $93,04 \%$ & $99,26 \%$ \\
\hline 24 & 5 & GG, 1 & 624,20 & 1189,50 & 3,22 & 2,50 & 5 & GG, 1 & $41,58 \%$ & $-11,32 \%$ & $93,51 \%$ & $98,77 \%$ \\
\hline 25 & 5 & $\mathrm{GG}, 2$ & 416,80 & 1839,90 & 2,93 & 2,60 & 5 & GG, 2 & $60,99 \%$ & $-72,19 \%$ & $94,08 \%$ & $98,72 \%$ \\
\hline 26 & 5 & GG, E & 476,60 & 1529,20 & 3,05 & 5,90 & 5 & GG, E & $55,40 \%$ & $-43,12 \%$ & $93,84 \%$ & $97,10 \%$ \\
\hline 27 & 5 & GG, 1,2 & 410,50 & 1656,60 & 2,67 & 3,00 & 5 & $\mathrm{GG}, 1,2$ & $61,58 \%$ & $-55,04 \%$ & $94,62 \%$ & $98,53 \%$ \\
\hline 28 & 5 & $\mathrm{GG}, 1,2, \mathrm{E}$ & 413,10 & 2111,10 & 3,48 & 5,30 & 5 & $\mathrm{GG}, 1,2, \mathrm{E}$ & $61,34 \%$ & $-97,58 \%$ & $92,99 \%$ & $97,39 \%$ \\
\hline 29 & 5 & $\mathrm{E}$ & 476,00 & 1544,60 & 2,95 & 2,80 & 5 & $\mathrm{E}$ & $55,45 \%$ & $-44,56 \%$ & $94,05 \%$ & $98,62 \%$ \\
\hline
\end{tabular}

Tomemos por exemplo a linha 28, em que foram aplicados tods os cortes; esses cortes produziram em média 413,1 mochilas enquanto a geração de colunas padrão produziu 1068,50 mochilas, o que representa $61,34 \%$ de redução no numero de mochilas (tabela 4.5). Em relação as iterações Simplex tivemos 2111,1 iterações (ou seja 413,1 mochilas e 1698 cortes duais), o que representa 97,58\% de aumento no número de iterações Simplex, feitas em 3,48 segundos representando uma redução de 92,99\% em relação ao tempo.

Nas tabelas (4.4) podemos notar que em todos os momentos em que os cortes foram 
introduzidos não obtivemos redução no número de iterações Simplex.

As tabelas (4.6) e (4.7) se referem a classe 3 da tabela 4.1

Tabela4.6: Valores Absolutos

Tabela 4.7: Porcentagem de redução

\begin{tabular}{|c|c|c|c|c|c|c|c|c|c|c|c|c|}
\hline & Múltiplos de m & Cortes & Mochilas & Iterações & Tempo & Cauda & Múltiplos de m & Cortes & Mochilas & Iterações & Tempo & Cauda \\
\hline 1 & $\mathrm{~m}=45$ & Sem Cortes & 313,30 & 313,30 & 12,77 & 65,90 & $\mathrm{~m}=45$ & Sem Cortes & $0 \%$ & $0 \%$ & $0 \%$ & $0 \%$ \\
\hline 2 & 0 & GG & 179,90 & 252,00 & 2,72 & 1,60 & 0 & GG & $45,58 \%$ & $19,57 \%$ & $78,72 \%$ & $97,57 \%$ \\
\hline 3 & 0 & GG, 1 & 111,20 & 263,50 & 2,85 & 1,20 & 0 & GG, 1 & $64,51 \%$ & $15,90 \%$ & $77,69 \%$ & $98,18 \%$ \\
\hline 4 & 0 & $\mathrm{GG}, 2$ & 46,90 & 579,50 & 1,99 & 2,20 & 0 & GG, 2 & $85,03 \%$ & $-84,97 \%$ & $84,39 \%$ & $96,66 \%$ \\
\hline 5 & 0 & GG, E & 66,10 & 426,60 & 2,81 & 0,80 & 0 & GG, E & $78,90 \%$ & $-36,16 \%$ & $78,01 \%$ & $98,79 \%$ \\
\hline 6 & 0 & GG, 1,2 & 43,00 & 517,90 & 1,87 & 3,60 & 0 & GG, 1,2 & $86,28 \%$ & $-65,30 \%$ & $85,40 \%$ & $94,54 \%$ \\
\hline 7 & 0 & $\mathrm{GG}, 1,2, \mathrm{E}$ & 38,00 & 600,20 & 1,70 & 1,80 & 0 & $\mathrm{GG}, 1,2, \mathrm{E}$ & $87,87 \%$ & $-91,57 \%$ & $86,69 \%$ & $97,27 \%$ \\
\hline 8 & 0 & $\mathrm{E}$ & 66,90 & 458,10 & 2,84 & 1,80 & 0 & $\mathrm{E}$ & $78,65 \%$ & $-46,22 \%$ & $77,74 \%$ & $97,27 \%$ \\
\hline 9 & 1 & GG & 187,00 & 241,20 & 4,04 & 0,30 & 1 & GG & $40,31 \%$ & $23,01 \%$ & $68,38 \%$ & $99,54 \%$ \\
\hline 10 & 1 & GG, 1 & 138,30 & 278,00 & 3,47 & 0,40 & 1 & GG, 1 & $55,86 \%$ & $11,27 \%$ & $72,85 \%$ & $99,39 \%$ \\
\hline 11 & 1 & GG, 2 & 79,20 & 540,40 & 1,80 & 2,50 & 1 & GG, 2 & $74,72 \%$ & $-72,49 \%$ & $85,92 \%$ & $96,21 \%$ \\
\hline 12 & 1 & GG, E & 91,60 & 402,10 & 1,99 & 1,10 & 1 & GG, E & $70,76 \%$ & $-28,34 \%$ & $84,44 \%$ & $98,33 \%$ \\
\hline 13 & 1 & $\mathrm{GG}, 1,2$ & 78,40 & 493,80 & 1,87 & 0,90 & 1 & $\mathrm{GG}, 1,2$ & $74,98 \%$ & $-57,61 \%$ & $85,37 \%$ & $98,63 \%$ \\
\hline 14 & 1 & $\mathrm{GG}, 1,2, \mathrm{E}$ & 76,70 & 594,30 & 1,66 & 3,20 & 1 & $\mathrm{GG}, 1,2, \mathrm{E}$ & $75,52 \%$ & $-89,69 \%$ & $87,01 \%$ & $95,14 \%$ \\
\hline 15 & 1 & $\mathrm{E}$ & 97,30 & 446,60 & 2,48 & 0,60 & 1 & $\mathrm{E}$ & $68,94 \%$ & $-42,55 \%$ & $80,55 \%$ & $99,09 \%$ \\
\hline 16 & 3 & GG & 234,30 & 259,70 & 3,60 & 0,20 & 3 & GG & $25,22 \%$ & $17,11 \%$ & $71,83 \%$ & $99,70 \%$ \\
\hline 17 & 3 & GG, 1 & 197,70 & 286,20 & 3,40 & 0,50 & 3 & GG, 1 & $36,90 \%$ & $8,65 \%$ & $73,36 \%$ & $99,24 \%$ \\
\hline 18 & 3 & GG, 2 & 159,20 & 422,90 & 1,88 & 0,50 & 3 & GG, 2 & $49,19 \%$ & $-34,98 \%$ & $85,27 \%$ & $99,24 \%$ \\
\hline 19 & 3 & GG, E & 166,60 & 355,50 & 2,57 & 1,00 & 3 & GG, E & $46,82 \%$ & $-13,47 \%$ & $79,88 \%$ & $98,48 \%$ \\
\hline 20 & 3 & $\mathrm{GG}, 1,2$ & 157,20 & 391,30 & 2,09 & 0,50 & 3 & $\mathrm{GG}, 1,2$ & $49,82 \%$ & $-24,90 \%$ & $83,61 \%$ & $99,24 \%$ \\
\hline 21 & 3 & $\mathrm{GG}, 1,2, \mathrm{E}$ & 153,20 & 421,20 & 1,72 & 0,90 & 3 & $\mathrm{GG}, 1,2, \mathrm{E}$ & $51,10 \%$ & $-34,44 \%$ & $86,51 \%$ & $98,63 \%$ \\
\hline 22 & 3 & $\mathrm{E}$ & 170,80 & 369,50 & 2,68 & 0,70 & 3 & $\mathrm{E}$ & $45,48 \%$ & $-17,94 \%$ & $79,02 \%$ & $98,94 \%$ \\
\hline 23 & 5 & GG & 246,40 & 248,10 & 2,62 & 0,30 & 5 & GG & $21,35 \%$ & $20,81 \%$ & $79,48 \%$ & $99,54 \%$ \\
\hline 24 & 5 & $\mathrm{GG}, 1$ & 240,10 & 250,70 & 2,60 & 0,60 & 5 & GG, 1 & $23,36 \%$ & $19,98 \%$ & $79,66 \%$ & $99,09 \%$ \\
\hline 25 & 5 & GG, 2 & 229,70 & 274,10 & 2,11 & 0,30 & 5 & GG, 2 & $26,68 \%$ & $12,51 \%$ & $83,46 \%$ & $99,54 \%$ \\
\hline 26 & 5 & GG, E & 236,00 & 269,70 & 2,64 & 0,30 & 5 & GG, E & $24,67 \%$ & $13,92 \%$ & $79,37 \%$ & $99,54 \%$ \\
\hline 27 & 5 & $\mathrm{GG}, 1,2$ & 228,50 & 268,70 & 2,13 & 0,50 & 5 & $\mathrm{GG}, 1,2$ & $27,07 \%$ & $14,24 \%$ & $83,29 \%$ & $99,24 \%$ \\
\hline 28 & 5 & $\mathrm{GG}, 1,2, \mathrm{E}$ & 227,50 & 268,40 & 2,11 & 0,70 & 5 & $\mathrm{GG}, 1,2, \mathrm{E}$ & $27,39 \%$ & $14,33 \%$ & $83,50 \%$ & $98,94 \%$ \\
\hline 29 & 5 & $\mathrm{E}$ & 232,90 & 256,80 & 2,46 & 0,30 & 5 & $\mathrm{E}$ & $25,66 \%$ & $18,03 \%$ & $80,74 \%$ & $99,54 \%$ \\
\hline
\end{tabular}

Tomemos por exemplo a linha 26, em que foram aplicados os cortes básico E e cortes de Gilmore e Gomory; esses cortes produziram em média 236 mochilas enquanto a geração de colunas padrão produziu 313,3 mochilas, o que representa $24,67 \%$ de redução no numero de mochilas (tabela 4.7). Em relação as iterações Simplex tivemos 269,7 iterações (ou seja 236 mochilas e 33,7 cortes duais), o que representa 13,92\% de redução no número de iterações Simplex , feitas em 2,64 segundos representando uma redução de $79,37 \%$ em relação ao tempo.

Nas tabelas acima podemos notar o mesmo comportamento que nas tabelas (4.2) e (4.3), ou seja, maior redução de mochilas e maior número de iterações quando os cortes duais atuam desde o início. Quando são introduzidos após $5^{*} m$ iterações a redução de mochila diminui e conseguimos também uma redução no número de iterações Simplex. 
As tabelas (4.8) e (4.9) se referem a classe 4 da tabela 4.1

Tabela4.8: Valores Absolutos

Tabela 4.9: Porcentagem de redução

\begin{tabular}{|c|c|c|c|c|c|c|c|c|c|c|c|c|}
\hline & Múltiplos de m & Cortes & Mochilas & Iterações & Tempo & Cauda & Múltiplos de m & Cortes & Mochilas & Iterações & Tempo & Cauda \\
\hline 1 & $\mathrm{~m}=70$ & Sem Cortes & 952,00 & 952,00 & 48,76 & 337,60 & $\mathrm{~m}=45$ & Sem Cortes & $0 \%$ & $0 \%$ & $0 \%$ & $0 \%$ \\
\hline 2 & 0 & GG & 337,00 & 558,00 & 2,51 & 2,00 & 0 & GG & $64,60 \%$ & $41,39 \%$ & $94,85 \%$ & $99,41 \%$ \\
\hline 3 & 0 & GG, 1 & 145,00 & 477,70 & 2,34 & 1,50 & 0 & GG, 1 & $84,77 \%$ & $49,82 \%$ & $95,21 \%$ & $99,56 \%$ \\
\hline 4 & 0 & GG, 2 & 58,50 & 1251,20 & 2,54 & 3,50 & 0 & GG, 2 & $93,86 \%$ & $-31,43 \%$ & $94,79 \%$ & $98,96 \%$ \\
\hline 5 & 0 & GG, E & 83,30 & 780,20 & 1,99 & 5,30 & 0 & GG, E & $91,25 \%$ & $18,05 \%$ & $95,93 \%$ & $98,43 \%$ \\
\hline 6 & 0 & GG, 1,2 & 54,80 & 1026,80 & 2,31 & 2,40 & 0 & $\mathrm{GG}, 1,2$ & $94,24 \%$ & $-7,86 \%$ & $95,26 \%$ & $99,29 \%$ \\
\hline 7 & 0 & $\mathrm{GG}, 1,2, \mathrm{E}$ & 50,10 & 1217,00 & 2,23 & 5,00 & 0 & $\mathrm{GG}, 1,2, \mathrm{E}$ & $94,74 \%$ & $-27,84 \%$ & $95,42 \%$ & $98,52 \%$ \\
\hline 8 & 0 & $\mathrm{E}$ & 86,50 & 849,70 & 1,88 & 2,20 & 0 & $\mathrm{E}$ & $90,91 \%$ & $10,75 \%$ & $96,15 \%$ & $99,35 \%$ \\
\hline 9 & 1 & GG & 377,50 & 578,80 & 2,29 & 1,50 & 1 & GG & $60,35 \%$ & $39,20 \%$ & $95,31 \%$ & $99,56 \%$ \\
\hline 10 & 1 & GG, 1 & 193,80 & 514,10 & 2,18 & 0,70 & 1 & GG, 1 & $79,64 \%$ & $46,00 \%$ & $95,54 \%$ & $99,79 \%$ \\
\hline 11 & 1 & GG, 2 & 121,80 & 1268,10 & 2,46 & 6,10 & 1 & GG, 2 & $87,21 \%$ & $-33,20 \%$ & $94,96 \%$ & $98,19 \%$ \\
\hline 12 & 1 & GG, E & 141,30 & 866,30 & 2,08 & 2,30 & 1 & GG, E & $85,16 \%$ & $9,00 \%$ & $95,73 \%$ & $99,32 \%$ \\
\hline 13 & 1 & GG, 1,2 & 115,50 & 987,60 & 2,11 & 3,80 & 1 & $\mathrm{GG}, 1,2$ & $87,87 \%$ & $-3,74 \%$ & $95,68 \%$ & $98,87 \%$ \\
\hline 14 & 1 & $\mathrm{GG}, 1,2, \mathrm{E}$ & 113,90 & 1201,50 & 2,22 & 3,90 & 1 & $\mathrm{GG}, 1,2, \mathrm{E}$ & $88,04 \%$ & $-26,21 \%$ & $95,45 \%$ & $98,84 \%$ \\
\hline 15 & 1 & $\mathrm{E}$ & 144,20 & 899,90 & 2,04 & 2,50 & 1 & $\mathrm{E}$ & $84,85 \%$ & $5,47 \%$ & $95,81 \%$ & $99,26 \%$ \\
\hline 16 & 3 & GG & 433,90 & 564,30 & 2,29 & 1,10 & 3 & GG & $54,42 \%$ & $40,72 \%$ & $95,30 \%$ & $99,67 \%$ \\
\hline 17 & 3 & GG, 1 & 314,10 & 590,90 & 2,27 & 1,50 & 3 & GG, 1 & $67,01 \%$ & $37,93 \%$ & $95,33 \%$ & $99,56 \%$ \\
\hline 18 & 3 & GG, 2 & 250,30 & 1162,40 & 2,27 & 2,40 & 3 & GG, 2 & $73,71 \%$ & $-22,10 \%$ & $95,35 \%$ & $99,29 \%$ \\
\hline 19 & 3 & GG, E & 265,80 & 839,10 & 2,13 & 2,70 & 3 & GG, E & $72,08 \%$ & $11,86 \%$ & $95,64 \%$ & $99,20 \%$ \\
\hline 20 & 3 & $\mathrm{GG}, 1,2$ & 246,80 & 1010,00 & 2,20 & 2,00 & 3 & $\mathrm{GG}, 1,2$ & $74,08 \%$ & $-6,09 \%$ & $95,48 \%$ & $99,41 \%$ \\
\hline 21 & 3 & $\mathrm{GG}, 1,2, \mathrm{E}$ & 244,70 & 1199,90 & 2,29 & 4,30 & 3 & $\mathrm{GG}, 1,2, \mathrm{E}$ & $74,30 \%$ & $-26,04 \%$ & $95,30 \%$ & $98,37 \%$ \\
\hline 22 & 3 & $\mathrm{E}$ & 271,50 & 869,20 & 2,09 & 2,30 & 3 & $\mathrm{E}$ & $71,48 \%$ & $8,70 \%$ & $95,71 \%$ & $99,32 \%$ \\
\hline 23 & 5 & GG & 533,60 & 623,90 & 2,65 & 1,10 & 5 & GG & $43,95 \%$ & $34,46 \%$ & $94,57 \%$ & $99,67 \%$ \\
\hline 24 & 5 & GG, 1 & 448,60 & 714,80 & 2,37 & 1,30 & 5 & GG, 1 & $52,88 \%$ & $24,92 \%$ & $95,14 \%$ & $99,61 \%$ \\
\hline 25 & 5 & GG, 2 & 381,40 & 1080,70 & 2,19 & 3,90 & 5 & GG, 2 & $59,94 \%$ & $-13,52 \%$ & $95,51 \%$ & $98,84 \%$ \\
\hline 26 & 5 & GG, E & 396,30 & 865,70 & 2,43 & 2,60 & 5 & GG, E & $58,37 \%$ & $9,07 \%$ & $95,01 \%$ & $99,23 \%$ \\
\hline 27 & 5 & GG, 1,2 & 377,70 & 968,90 & 2,27 & 3,30 & 5 & $\mathrm{GG}, 1,2$ & $60,33 \%$ & $-1,78 \%$ & $95,34 \%$ & $99,02 \%$ \\
\hline 28 & 5 & $\mathrm{GG}, 1,2, \mathrm{E}$ & 377,80 & 1119,90 & 2,43 & 4,10 & 5 & $\mathrm{GG}, 1,2, \mathrm{E}$ & $60,32 \%$ & $-17,64 \%$ & $95,02 \%$ & $98,79 \%$ \\
\hline 29 & 5 & $\mathrm{E}$ & 403,50 & 913,30 & 2,51 & 2,80 & 5 & $\mathrm{E}$ & $57,62 \%$ & $4,07 \%$ & $94,85 \%$ & $99,17 \%$ \\
\hline
\end{tabular}

Tomemos por exemplo a linha 3 e a linha 5, em que foram aplicados os cortes básico 1 e cortes de Gilmore e Gomory (linha 3) e os cortes E e cortes de Gilmore e Gomory (linha 5). Na linha 3 tivemos 145 mochilas por 477,7 iterações Simplex feitas em 2,34 segundos, enquanto na linha 5 tivemos 83,3 mochilas por 780,20 iterações Simplex feitas em 1,99 segundos. Observemos que a geração de colunas padrão obteve 952,00 mochilas em 48,76 segundos. Comparando esses dois cortes constatamos que o corte da linha 5 obteve $91 \%$ de redução no numero de mochilas enquanto que o corte da linha 3 obteve $84 \%$ de redução, porém obtiveram 50\% e 18\% de redução no número de iterações Simplex respectivamente. Em média os cortes E tiveram maior redução no número de mochilas porém obtiveram pior desempenho em relação ao número de iterações Simplex. 
Estudando a influencia do tamanho dos itens nos cortes, testamos alguns problemas considerando um intervalo mais restrito $\left([0.01 ; 0.3]^{*} \mathrm{~L}\right)$. Para ilustrarmos o resultado mostramos o exemplo com barra de $500 \mathrm{~cm}$ e 70 itens.

Tabela4.10: Valores Absolutos

Tabela 4.11: Porcentagem de redução

\begin{tabular}{|c|c|c|c|c|c|c|c|c|c|c|c|c|}
\hline & Múltiplos de m & Cortes & Mochilas & Iterações & Tempo & Cauda & Múltiplos de m & Cortes & Mochilas & Iterações & Tempo & Cauda \\
\hline 1 & $\mathrm{~m}=70$ & Sem Cortes & 659,50 & 659,50 & 1,27 & 511,50 & $\mathrm{~m}=45$ & Sem Cortes & $0 \%$ & $0 \%$ & $0 \%$ & $0 \%$ \\
\hline 2 & 0 & GG & 132,70 & 144,00 & 0,71 & 0,10 & 0 & GG & $79,88 \%$ & $78,17 \%$ & $44,23 \%$ & $99,98 \%$ \\
\hline 3 & 0 & GG, 1 & 143,10 & 327,90 & 0,60 & 0,10 & 0 & GG, 1 & $78,30 \%$ & $50,28 \%$ & $52,69 \%$ & $99,98 \%$ \\
\hline 4 & 0 & GG, 2 & 17,90 & 1001,80 & 1,12 & 2,20 & 0 & GG, 2 & $97,29 \%$ & $-51,90 \%$ & $12,24 \%$ & $99,57 \%$ \\
\hline 5 & 0 & GG, E & 67,00 & 466,50 & 0,64 & 1,90 & 0 & GG, E & $89,84 \%$ & $29,26 \%$ & $49,74 \%$ & $99,63 \%$ \\
\hline 6 & 0 & $\mathrm{GG}, 1,2$ & 16,60 & 915,50 & 0,92 & 1,60 & 0 & $\mathrm{GG}, 1,2$ & $97,48 \%$ & $-38,82 \%$ & $27,56 \%$ & $99,69 \%$ \\
\hline 7 & 0 & $\mathrm{GG}, 1,2, \mathrm{E}$ & 16,70 & 1062,10 & 1,30 & 2,10 & 0 & $\mathrm{GG}, 1,2, \mathrm{E}$ & $97,47 \%$ & $-61,05 \%$ & $-2,31 \%$ & $99,59 \%$ \\
\hline 8 & 0 & $\mathrm{E}$ & 68,90 & 458,80 & 0,63 & 1,20 & 0 & $\mathrm{E}$ & $89,55 \%$ & $30,43 \%$ & $50,25 \%$ & $99,77 \%$ \\
\hline 9 & 1 & GG & 138,10 & 141,70 & 0,70 & 0,10 & 1 & GG & $79,06 \%$ & $78,51 \%$ & $44,72 \%$ & $99,98 \%$ \\
\hline 10 & 1 & GG, 1 & 142,80 & 191,00 & 0,68 & 0,00 & 1 & GG, 1 & $78,35 \%$ & $71,04 \%$ & $46,82 \%$ & $100,00 \%$ \\
\hline 11 & 1 & GG, 2 & 74,90 & 352,90 & 0,66 & 1,00 & 1 & GG, 2 & $88,64 \%$ & $46,49 \%$ & $48,05 \%$ & $99,80 \%$ \\
\hline 12 & 1 & GG, E & 98,20 & 253,40 & 0,69 & 1,30 & 1 & GG, E & $85,11 \%$ & $61,58 \%$ & $45,59 \%$ & $99,75 \%$ \\
\hline 13 & 1 & GG, 1,2 & 75,60 & 374,00 & 0,67 & 2,10 & 1 & $\mathrm{GG}, 1,2$ & $88,54 \%$ & $43,29 \%$ & $47,19 \%$ & $99,59 \%$ \\
\hline 14 & 1 & $\mathrm{GG}, 1,2, \mathrm{E}$ & 74,70 & 410,00 & 0,73 & 1,80 & 1 & $\mathrm{GG}, 1,2, \mathrm{E}$ & $88,67 \%$ & $37,83 \%$ & $42,52 \%$ & $99,65 \%$ \\
\hline 15 & 1 & $\mathrm{E}$ & 98,40 & 256,20 & 0,71 & 1,60 & 1 & $\mathrm{E}$ & $85,08 \%$ & $61,15 \%$ & $44,48 \%$ & $99,69 \%$ \\
\hline 16 & 3 & GG & 146,20 & 146,30 & 0,73 & 0,00 & 3 & GG & $77,83 \%$ & $77,82 \%$ & $42,40 \%$ & $100,00 \%$ \\
\hline 17 & 3 & GG, 1 & 145,80 & 148,90 & 0,73 & 0,10 & 3 & GG, 1 & $77,89 \%$ & $77,42 \%$ & $42,75 \%$ & $99,98 \%$ \\
\hline 18 & 3 & GG, 2 & 135,30 & 179,50 & 0,74 & 0,30 & 3 & GG, 2 & $79,48 \%$ & $2,780 \%$ & $41,78 \%$ & $99,94 \%$ \\
\hline 19 & 3 & GG, E & 139,00 & 160,40 & 0,77 & 0,44 & 3 & GG, E & $78,92 \%$ & $75,68 \%$ & $39,34 \%$ & $99,92 \%$ \\
\hline 20 & 3 & GG, 1,2 & 135,30 & 179,50 & 0,74 & 0,30 & 3 & GG, 1,2 & $79,48 \%$ & $72,78 \%$ & $41,66 \%$ & $99,94 \%$ \\
\hline 21 & 3 & $\mathrm{GG}, 1,2, \mathrm{E}$ & 135,30 & 182,60 & 0,76 & 0,40 & 3 & $\mathrm{GG}, 1,2, \mathrm{E}$ & $79,48 \%$ & $72,31 \%$ & $44,69 \%$ & $99,92 \%$ \\
\hline 22 & 3 & $\mathrm{E}$ & 138,90 & 160,80 & 0,79 & 0,40 & 3 & $\mathrm{E}$ & $78,94 \%$ & $75,62 \%$ & $38,22 \%$ & $99,92 \%$ \\
\hline
\end{tabular}

Tomemos por exemplo a linha 19, em que foram aplicados os cortes de Gilmore e Gomory e básico E; esses cortes produziram em média 139 mochilas e produziram também 160,4 iterações Simplex, o que significa que tivemos 21,4 cortes duais enquanto a geração de colunas padrão produziu 659,5 mochilas, o que representa 78,92\% de redução no número de mochilas (tabela 4.11). Ao analisarmos o número de mochilas durante a introdução dos cortes duais verificamos que já após 140 iterações $\left(2^{*} m\right)$ o desempenho dos cortes duais (linha 16 a 22) se equiparam. Ao introduzirmos os cortes duais após mais iterações verificamos que todos os cortes apresentam o mesmo desempenho pois poucos cortes entram na base.

Como os itens possuem tamanhos próximos, a possibilidade de utilizarmos um item para cortarmos outro menor mais de uma vez diminui, logo cortes do tipo 3 e tipo 1 apresentaram pouca diferença na economia de mochila se disparados após muitas iterações Simplex, porém, se os cortes são considerados desde o início ainda apresentaram boa economia.

Inicialmente verificamos a variação das variáveis duais no caso do Método Simplex com geração de coluna ( como podemos verificar na figura 1.5) em que as variáveis 
variaram muito entre 0 e 4, apesar do gráfico tenha variado entre 0 e 16, podemos agora verificar a variação das variáveis duais com os cortes duais:

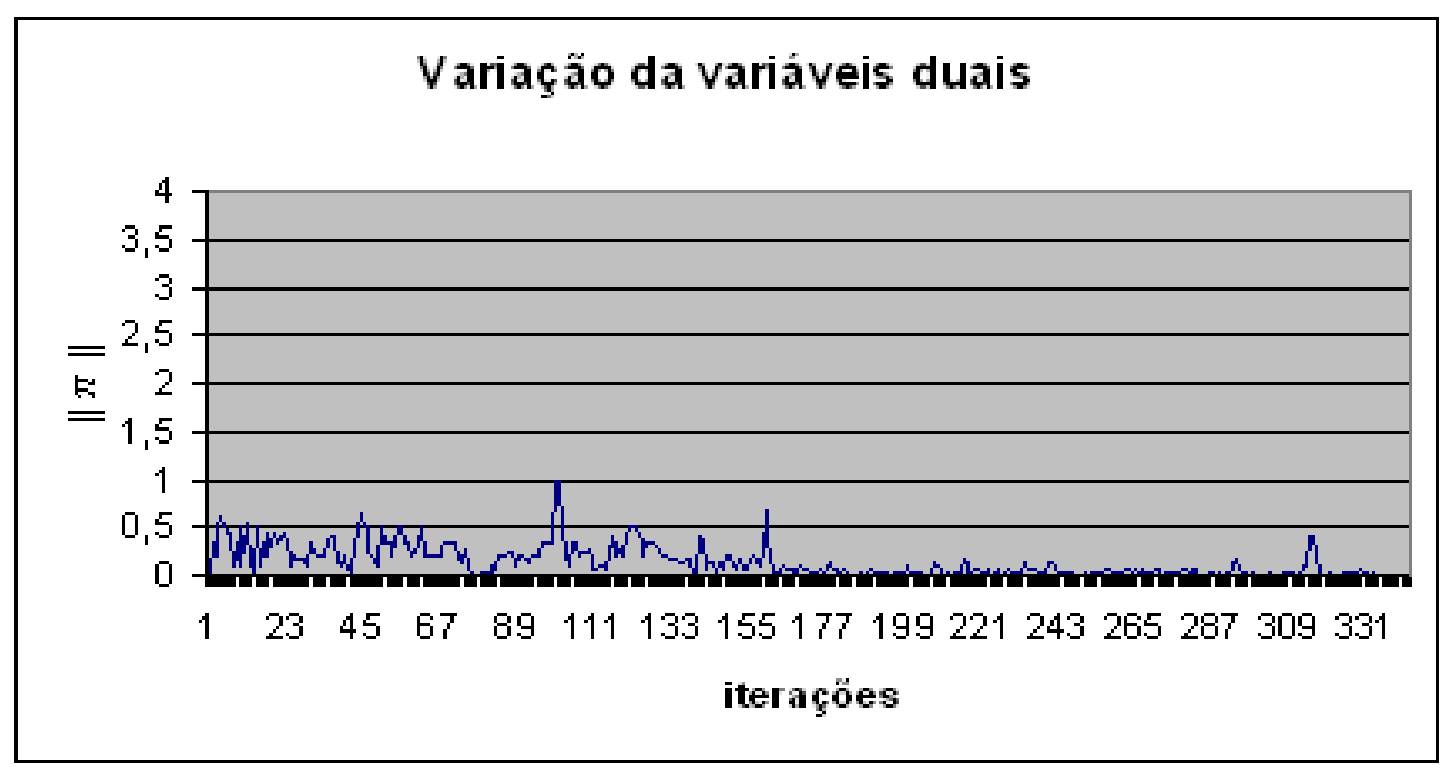

Figura 4.1: Variação da norma do vetor multiplicador simplex, caso corte dual básico $|S|=1$.

Analisando os gráficos verificamos que o intervalo dos valores das variáveis duais diminuíram quando a eficiência dos cortes aumenta. Na figura (1.5) que representa a geração de colunas padrão o intervalo das variáveis está entre $[0,16]$ e com a utilização dos cortes duais os intervalos ficaram entre $[0,1],[0,2.2]$ e $[0,0.8]$ respectivamente. Podemos constatar que os cortes duais estabilizaram a geração de colunas diminuindo o intervalo e a oscilação das variáveis duais. 


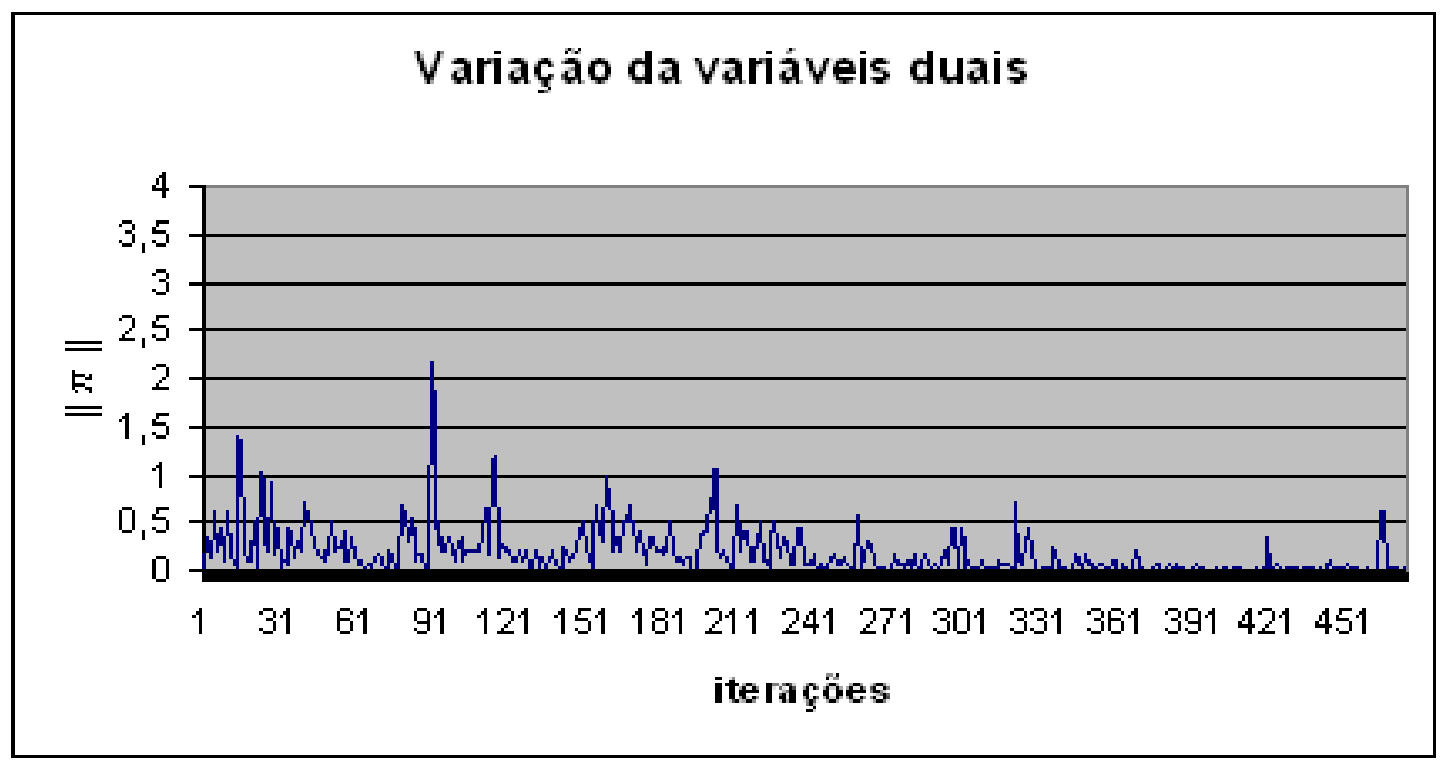

Figura 4.2: Variação da norma do vetor multiplicador simplex, caso corte dual estendido $|S|=1$.

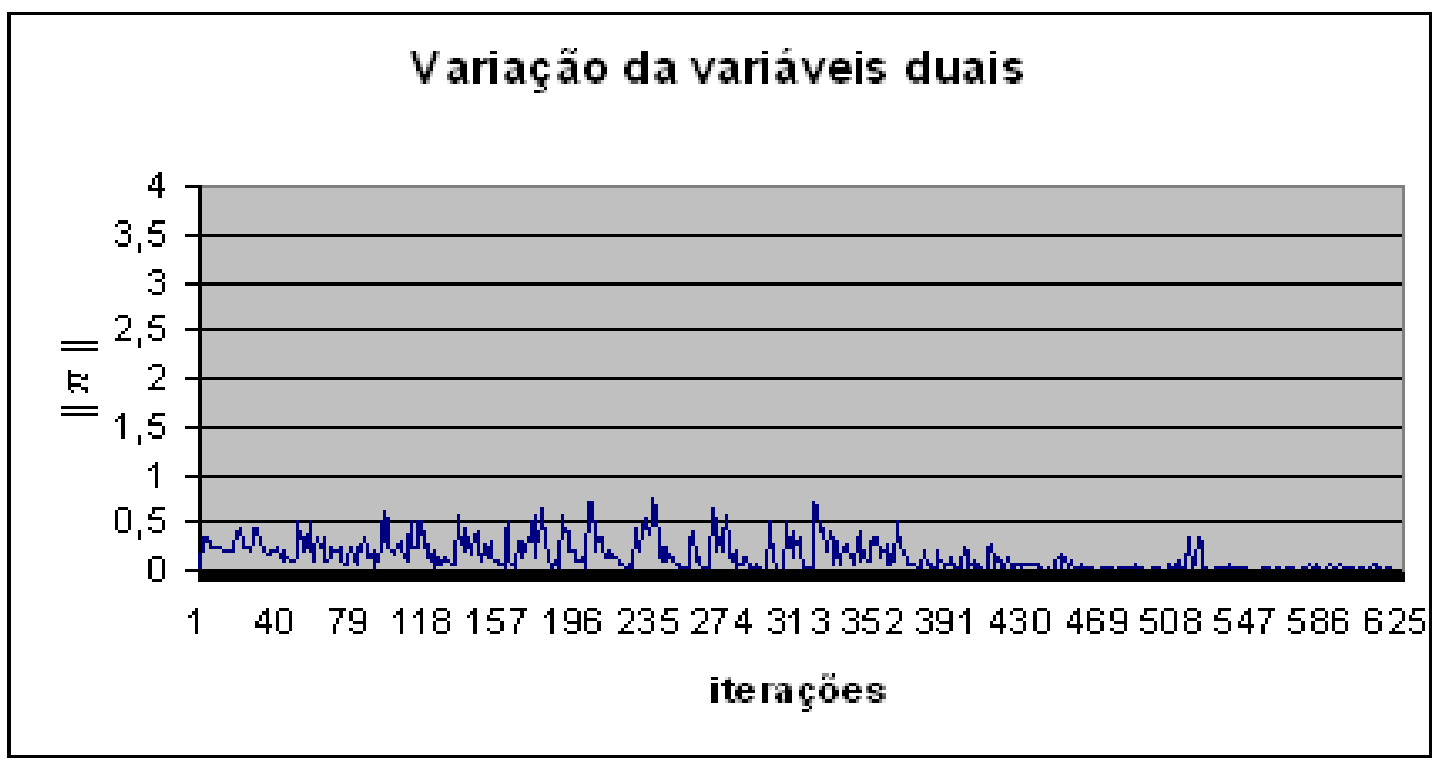

Figura 4.3: Variação da norma do vetor multiplicador simplex, caso com todos os cortes duais. 


\section{Capítulo 5}

\section{Conclusões e Perspectivas}

Estudamos o Método Simplex com a técnica de geração de colunas aplicado em problemas de otimização linear. Utilizamos a estratégia de cortes duais para acelerar e estabilizar o Método Simplex com geração de colunas. Aplicamos uma família de cortes duais de Valério de Carvalho e propomos uma extensão desses cortes para os itens e para os objetos. Fizemos testes computacionais que mostraram que as extensões para os cortes duais dos itens se mostraram eficazes quanto à redução no número de mochilas, tempo e cauda. Portanto, verificamos que ao diminuir o número de mochilas aumentamos o número de iterações Simplex. Em relação aos objetos apresentamos uma extensão dos cortes duais propostos por Valério de Carvalho e realizamos alguns testes computacionais iniciais, porém, a conclusão desses testes estão como perspectivas futuras. Testamos também a variação das variáveis duais e verificamos que os cortes duais as diminuíram significativamente.

Em relação as perspectivas podemos investigar algumas extensões;

- Estudar extensões para os cortes duais dos itens em que $|S|=2$;

- Estudar implemetações dos cortes duais para os objetos;

- Estudar extensões paras os cortes duais em problemas de mais de uma dimensão;

- Aplicar os cortes duais para outros problemas, como por exemplo, problemas de roteamento de veículos. 


\section{Bibliografia}

[1] AREnAleS, M. N., MORABITO, R., H.H. Yanasse "O Problema de Corte e Empacotamento ". Livro-texto de Mini curso, XXXVI SBPO - São João del Rei - MG, (2004).

[2] BEN AMOR, H., DESROSIERS, J., VAlÉRIO DE CARVAlHO, J. M., "Dualoptimal inequalities for stabilized column generation". Les Cahiers du GERAD, G2003-20 (2003).

[3] BEN AMOR, H. and DESROSIERS , J. (2003) "A Proximal Trust Region Algorithm for Column Generation Stabilization.". Les Cahiers du GERAD G-2003-43 (2003). To appear in Comp. \& OR.

[4] GILMORE, P. C., GOMORY, R. E., "A linear programming approach to the cutting stock problem". Operations Research, 9: 848-859 (1961).

[5] GILMORE, P. C., GOMORY, R. E., "A linear programming approach to the cutting stock problem - Part II'. Operations Research, 11: 863-888 (1963).

[6] GILMORE, P. C., GOMORY, R. E., "Multi-stage cutting stock problems of two and more dimensions". Operations Research, 13: 94-120 (1965).

[7] HAESSLER, R. W., "A note on computational modifications to the Gilmore-Gomory cutting stock algorithm". Operations Research, 28: 1001-1005 (1980).

[8] HINXMAN, A., "The trim-loss and assortment problems: a survey". European Journal of Operational Research, 5: 8-18 (1980).

[9] L ÜBBECKE M. E. "Dual variable based fathoming in dynamic programs for column generation ". European Journal of Operational Research, 162: 122-125 (2005). 
[10] MARSTEN, R.E., "The use of the boxstep method in discrete optimization". Mathematical Programming Study, 3, 127-144 (1975).

[11] Merle, O. , VIllenueve, D., Desrosiers, J., HANSEN, P., "Stabilized column generation". Discrete Mathematics, 194, 229-237 (1999).

[12] POLDI, K. C., "Algumas extensões do problema de corte de estoque". Tese de Mestrado, ICMC - USP, (2003).

[13] VALÉRIO DE CARVALHO, J. M., "Using extra dual cuts to accelerate convergence in column generation". INFORMS Journal on Computing (2003). 


\section{Apêndice A}

\section{Método Simplex e a técnica de geração de colunas}

Numa iteração qualquer do Método Simplex, uma base factível é conhecida (denotamos por $B$ a matriz básica), com a qual é calculado o vetor multiplicador:

$$
\pi^{T}=c_{B}^{T} B^{-1}
$$

( $c_{B}$ é o vetor dos custos relativos). Um dos passos do Método Simplex consiste em determinar a coluna a entrar na base, cujo custo relativo $\left(\hat{c}_{j}=c_{j}-\pi^{T} \mathbf{a}_{\mathbf{j}}\right)$ seja negativo.

Uma escolha usual, chamada regra de Dantzig, é dada por:

$$
c_{k}-\pi \mathbf{a}_{\mathbf{k}}=\operatorname{Min}\left\{c_{j}-\pi \mathbf{a}_{\mathbf{j}}, j=1,2, \cdots, n\right\}
$$

Se $c_{k}-\pi \mathbf{a}_{\mathbf{k}}=0$ (as variáveis básicas, incluídas no cálculo do mínimo acima, têm custos relativos nulos), então a solução básica $\left(x_{B}=B^{-1} b\right)$ é ótima, caso contrário, a coluna $a_{k}$ entra na base. Como o número de variáveis, $n$, é muito grande para o problema de corte de estoque, o mínimo em (A.2) para o modelo (2.2) pode ser obtido, observandose que uma coluna $j$ qualquer digamos $\mathbf{a}_{\mathbf{j}}=\left(a_{1}, a_{2}, \ldots, a_{m}\right)^{T}$, corresponde a um padrão de corte unidimensional, então (A.2) pode ser reescrito por:

$$
\min c_{j}-\sum_{i=1}^{m} \pi_{i} \mathbf{a}_{\mathbf{i}}, \text { tal que }: \sum_{i=1}^{m} \ell_{i} \mathbf{a}_{\mathbf{i}} \leq L, \quad \mathbf{a}_{\mathbf{i}} \geq 0 \text { interio }
$$


se a função objetivo $f(\mathbf{x})$ for dada por: $f(\mathbf{x})=\sum_{j=1}^{n} x_{j}$, então $c_{j}=1, \forall j$. Assim, (A.3) pode ser reescrito por:

$$
\begin{aligned}
& \text { maximizar } \sum_{i=1}^{m} \pi_{i} a_{i} \\
& \text { sujeito } a:\left\{\begin{array}{l}
\sum_{i=1}^{m} l_{i} a_{i} \leq L \\
a_{i} \geq 0 \text { e inteiro } i=1, \cdots, m
\end{array}\right.
\end{aligned}
$$

(sendo que $c_{j}$ depende de $a_{j}$, no caso $c_{j}=L-\sum_{i=1}^{m} \ell_{i} a_{i}$, ou seja, perda, o problema acima é ligeiramente modificado).

Assim, a solução de (A.4) fornece a coluna; $\left(a_{1}, a_{2}, \ldots, a_{m}\right)^{T}$ com o menor custo relativo $\left(c_{j}=1\right)$ :

$$
\hat{c}=1-\sum_{i=1}^{m} \pi_{i} \mathbf{a}_{\mathbf{i}}
$$

Se $\hat{c}=0$, então a solução é ótima, senão, $\hat{c}<0$, a coluna $\left(a_{1}, a_{2}, \ldots, a_{m}\right)^{T}$ entra na base (a coluna a sair da base segue os passos usuais do Método Simplex).

De outra forma, a coluna para entrar na base foi gerada por (A.4), o qual implicitamente representa todas as colunas do problema de corte.

\section{A.0.10 Algoritmo do Método Simplex com Geração de Colunas Aplicado no Problema de Corte de Peças em Estoque}

Abaixo apresentamos o algoritmo do Método Simplex com a geração de colunas:

\section{FASE I:}

Determinamos uma base inicial $B$ que será composta por padrões de cortes homogêneos, ou seja; 
$B=\left(\begin{array}{cccc}\left\lfloor\frac{L}{l_{1}}\right\rfloor & 0 & \ldots & 0 \\ 0 & \left\lfloor\frac{L}{l_{2}}\right\rfloor & \ldots & 0 \\ \vdots & \vdots & \ddots & \vdots \\ 0 & 0 & \ldots & \left\lfloor\frac{L}{l_{m}}\right\rfloor\end{array}\right)$

Faça: PARE=Falso e IT $=1$

$\{$ A variável lógica PARE terá valor FALSO até que a condição de otimalidade seja verificada e IT é o número da iteração atual \}

\section{FASE II:}

Enquanto PARE=Falso, faça:

\{nício da iteração Simplex\}

1 Solução Básica: $B x_{B}=b$.

2 Teste de Otimalidade.

2.1 Vetor multiplicador Simplex: $B^{T} \pi=c_{B}$

2.2 Custo relativo: Resolva o Problema da Mochila:

$\operatorname{Max} \pi_{1} a_{1}+\pi_{2} a_{2}+\cdots+\pi_{m} a_{m}$
s.a. $\left\{\begin{array}{c}l_{1} a_{1}+l_{2} a_{2}+\cdots+l_{m} a_{m} \leq L \\ a_{i} \geq 0 \text { e inteiro }\end{array}\right.$

Seja $a=\left(a_{1}, a_{2}, \ldots, a_{m}\right)^{T}$ a solução ótima do Problema da mochila.

Para o custo da mochila utilizamos $\pi$ para minimizar o número de rolos e $\pi+\ell$ para minimizar a perda total. 
Se $1-\pi^{T} a=0$ para o caso de minimizar o número de rolos ou $L-\pi^{T} a=0$ para o caso da perda total.

então PARE $=$ VERDADEIRO \{solução atual é ótima e foi obtida em IT iterações \}.

\section{início-senão:}

3 Determine as coordenadas básicas da direção simplex $\bar{a}$

$$
B \cdot \bar{a}=-a
$$

3.1 Determinação do Tamanho do Passo

Encontre $l$ tal que:

$$
-\frac{x_{l}}{\bar{a}_{l}}=\min \left\{-\frac{x_{i}}{\bar{a}_{i}} \mid \bar{a}_{i}<0\right\}
$$

\subsection{Atualização}

Atualize a base, colocando a coluna $\bar{a}$ na $\ell$-ésima coluna da matriz $B$.

Faça: $\mathrm{IT}=\mathrm{IT}+1$

\section{fim-senão}

Fim do algoritmo 


\section{Apêndice B}

\section{Prova da afirmação da seção 2.1.1}

Considere o seguinte problema (que minimiza a perda):

$$
\begin{aligned}
& \text { minimizar } f(x)=\sum_{j=1}^{n} c_{j} x_{j} \\
& \text { sujeito } a: A x=b, \quad x \geq 0 \text { e inteiro }
\end{aligned}
$$

Como $c_{j}=L-\left(a_{1 j} \ell_{1}+a_{2 j} \ell_{2}+\cdots+a_{m j} \ell_{m}\right)$, a função objetivo em (B.1) é:

$$
f(x)=\sum_{j=1}^{n}\left(L-\sum_{i=1}^{m} \ell_{i} a_{i j}\right) x_{j}=L \sum_{j=1}^{n} x_{j}-\sum_{j=1}^{n} \sum_{i=1}^{m} \ell_{i} a_{i j} x_{j}=L \sum_{j=1}^{n} x_{j}-\sum_{i=1}^{m} \ell_{i} \sum_{j=1}^{n} a_{i j} x_{j}
$$

Porém, $\sum_{j=1}^{n} a_{i j} x_{j}=b_{i}$, segue:

$$
f(x)=L \sum_{j=1}^{n} x_{j}-\sum_{i=1}^{m} \ell_{i} b_{i}
$$

Como $L>0$ e $\sum_{i=1}^{m} \ell_{i} b_{i}$ são constantes, temos que o problema de minimizar $f(x)$ (minimizar perda) é equivalente ao de minimizar o total de barras a serem cortadas: minimizar $f(x)=$ minimizar $L \sum_{j=1}^{n} x_{j}-\sum_{i=1}^{m} \ell_{i} b_{i}=L\left[\operatorname{minimizar} \sum_{j=1}^{n} x_{j}\right]-\sum_{i=1}^{m} \ell_{i} b_{i}$. 